OPEN ACCESS

Edited by:

Amiram Ariel,

University of Haifa, Israel

Reviewed by:

Benjamin G. Dewals, University of Liège, Belgium

David Voehringer,

University of Erlangen Nuremberg,

Germany

${ }^{*}$ Correspondence:

Meera G. Nair

meera.nair@medsch.ucr.edu

Specialty section:

This article was submitted to

Inflammation,

a section of the journal

Frontiers in Immunology

Received: 16 May 2021

Accepted: 29 June 2021

Published: 19 July 2021

Citation:

Li J, Kim SY, Lainez NM, Coss D and

Nair MG (2021) Macrophage-

Regulatory T Cell Interactions Promote

Type 2 Immune Homeostasis Through

Resistin-Like Molecule $\alpha$.

Front. Immunol. 12:710406.

doi: 10.3389/fimmu.2021.710406

\section{Macrophage-Regulatory T Cell Interactions Promote Type 2 Immune Homeostasis Through Resistin-Like Molecule $\alpha$}

\author{
Jiang Li, Sang Yong Kim, Nancy M. Lainez, Djurdjica Coss and Meera G. Nair * \\ Division of Biomedical Sciences, School of Medicine, University of California Riverside, Riverside, CA, United States
}

RELM $\alpha$ is a small, secreted protein expressed by type 2 cytokine-activated "M2" macrophages in helminth infection and allergy. At steady state and in response to type 2 cytokines, RELM $\alpha$ is highly expressed by peritoneal macrophages, however, its function in the serosal cavity is unclear. In this study, we generated RELM $\alpha$ TdTomato (Td) reporter/ knockout ( $R \alpha^{T d}$ ) mice and investigated RELM $\alpha$ function in IL-4 complex (IL-4C)-induced peritoneal inflammation. We first validated the RELM $\alpha^{T d / T d}$ transgenic mice and showed that IL-4c injection led to the significant expansion of large peritoneal macrophages that expressed Td but not RELM $\alpha$ protein, while RELM $\alpha^{+/+}$mice expressed RELM $\alpha$ and not Td. Functionally, $\mathrm{RELM} \alpha^{\mathrm{Td} / T d}$ mice had increased $\mathrm{IL}-4$ induced peritoneal macrophage responses and splenomegaly compared to RELM ${ }^{+/+}$mice. Gene expression analysis indicated that $\mathrm{RELM} \alpha^{\mathrm{Td} / \mathrm{Td}}$ peritoneal macrophages were more proliferative and activated than $\mathrm{RELM} \alpha^{+/+}$ macrophages, with increased genes associated with $T$ cell responses, growth factor and cytokine signaling, but decreased genes associated with differentiation and maintenance of myeloid cells. We tested the hypothesis that $R \alpha^{T d / T d}$ macrophages drive aberrant $T$ cell activation using peritoneal macrophage and $T$ cell co-culture. There were no differences in $\mathrm{CD}^{+} \mathrm{T}$ cell effector responses when co-cultured with $\mathrm{RELM} \alpha^{+/+}$or $\mathrm{RELM} \alpha^{\mathrm{Td} / \mathrm{Td}}$ macrophages, however, RELM $\alpha^{\mathrm{Td} / T d}$ macrophages were impaired in their ability to sustain proliferation of FoxP3 ${ }^{+}$regulatory $\mathrm{T}$ cells (Treg). Supportive of the in vitro results, immunofluorescent staining of the spleens revealed significantly decreased FoxP3 ${ }^{+}$cells in the RELM $\alpha^{\text {Td/Td }}$ spleens compared to RELM $\alpha^{+/+}$spleens. Taken together, these studies identify a new RELM $\alpha$ regulatory pathway whereby RELM $\alpha$-expressing macrophages directly sustain Treg proliferation to limit type 2 inflammatory responses.

Keywords: splenomegaly, peritonitis, Treg, Th2 cytokine, M2 macrophage

\section{INTRODUCTION}

Macrophages are a dominant resident population within the peritoneal cavity with critical immune surveillance and homeostatic functions (1). As sentinels, they are rapid responders to microbial invasion resulting from injury of the serous organs, such as the spleen, liver and intestinal tract, and can be mobilized to traffic to the injured organ and mediate tissue repair (2). Peritoneal 
macrophages also perform homeostatic functions to support innate B1 cells (3), clear debris and apoptotic cells $(4,5)$, and dampen inflammation (6-8). On the other hand, dysregulated peritoneal macrophage responses are associated with diseases including peritonitis, bacterial dissemination, and cancer metastases (9-12). Identification of peritoneal macrophagederived factors and activation markers that cause beneficial or pathologic outcomes would provide insight into their biology and identify targets for treatment of serous cavity-associated disease.

Peritoneal macrophages, especially the monocyte-derived small peritoneal macrophages, express Resistin-like molecule $\alpha$ (RELM $\alpha$ ) under homeostatic conditions (13). In type 2 cytokinepolarized environments such as helminth infection or in vivo IL4 complex injection, RELM $\alpha$ expression is dramatically elevated reaching $100 \%$ expression by small and large peritoneal macrophages (14). RELM $\alpha$, also known as FIZZ1 and HIMF, was originally identified as a highly secreted protein in the lung during allergic airway inflammation (15), however, it is now well-recognized that RELM $\alpha$ is pleiotropically expressed throughout the body, and a signature gene expressed by M2polarized macrophages in response to multiple helminth infections $(16,17)$. RELM $\alpha$ expression is also triggered by other signals in addition to type 2 cytokines, for example by phagocytosis of apoptotic cells through scavenger receptors (18), or in response to hypoxia (19). Studies in pulmonary inflammation, hypertension and fibrosis, point to an inflammatory function for RELM $\alpha$ by promoting immune cell recruitment, fibroblast activation and proliferation associated with pathogenic fibrosis $(20,21)$. On the other hand, in response to tissue migratory helminth parasites, RELM $\alpha$ critically prevents fatal lung tissue damage, granulomatous inflammation, and promotes tissue repair $(22-28)$. Downstream regulatory mechanisms for RELM $\alpha$ include limiting $\mathrm{CD}^{+} \mathrm{T}$ cell polarization, promoting anti-inflammatory responses, and mediating collagen cross-linking associated with tissue healing $(26,29,30)$. RELM $\alpha$ also exhibits antibacterial properties by disrupting bacterial membranes for certain bacterial species (31).

Despite high expression levels of RELM $\alpha$ by peritoneal macrophages, whether RELM $\alpha$ affects the role of these cells in immune surveillance or homeostasis is unknown. In this study, we generated transgenic mice where RELM $\alpha$ is deleted and replaced with the TdTomato reporter protein $\left(\mathrm{R} \alpha^{\mathrm{Td}}\right)$ and investigated the consequence of RELM $\alpha$ deletion in a polarized type 2 cytokine environment caused by injection of IL-4 complexes. We first validated the $R \alpha$ transgenic mice and demonstrated successful deletion of RELM $\alpha$ and expression of TdTomato protein, which had an equivalent expression pattern to RELM $\alpha$. Next, we compared PBS and IL-4c injected $\mathrm{R}^{+/+}$ and $\mathrm{R} \alpha^{\mathrm{Td} / \mathrm{Td}}$ mice, where we identify a critical role for RELM $\alpha$ in limiting IL-4-induced peritoneal macrophage expansion, M1 macrophage activation, and splenomegaly. Gene expression analysis of sorted macrophages from $\mathrm{R}^{+/+}$and $\mathrm{R} \alpha^{\mathrm{Td} / \mathrm{Td}}$ mice revealed that RELM $\alpha$ deficiency leads the induction of genes promoting $\mathrm{T}$ cell response, growth factor and cytokine signaling, but decreased genes associated with differentiation and maintenance of myeloid cells. Combining macrophage-T cell co-cultures, and investigation of ex vivo $\mathrm{T}$ cell responses, we further identify a role for macrophage-derived RELM $\alpha$ in promoting regulatory $\mathrm{T}$ cell proliferation and the production of IL-10 and GM-CSF. Together, results from these studies validate the utility of $\mathrm{R} \alpha^{\mathrm{Td} / \mathrm{Td}}$ mice to track RELM $\alpha$ expression and identify a dual role for RELM $\alpha$ in limiting type 2 cytokine immunopathology by cell-intrinsic effects on macrophages and regulatory $\mathrm{T}$ cells.

\section{MATERIALS AND METHODS}

\section{Mice}

Retnla $^{T d}$ transgenic mice were generated by genOway (Lyon, France) by homologous recombination in C57BL/6 embryonic stem cells. Retnla Exon 2-4 was targeted using cre recombinase and Flp-mediated excision and replacement with the Td reporter gene, with a WPRE site (32) to enhance reporter expression and stability. The mice were crossed with the genOway proprietary cre-deleter mouse (pCMV driven cre) to generate constitutive Retnla ${ }^{\mathrm{Td}}$ mice. Retnla ${ }^{\mathrm{Td} /+}$ heterozygote mice were crossed with C57BL/6 mice to generate littermate homozygote (Td/Td) and WT $(+/+)$ mice after three generations, then bred in-house. Arginase $^{\text {YFP }}$ (Yarg) mice were available from Jackson labs. Mice were age matched (6 to 14 weeks old), sex-matched for experiments, and housed under an ambient temperature with a 12 hours light/12 hours dark cycle.

\section{IL-4 Complex (IL-4c) Injection}

Mice were injected intraperitoneally (i.p.) with $2.5 \mu \mathrm{g}$ of recombinant mouse IL-4 (Peprotech, Rock Hill, NJ) complexed to $12 \mu \mathrm{g} 11 \mathrm{~B} 11$ (Bio X Cell) in $100 \mu \mathrm{l}$ PBS or $100 \mu \mathrm{l}$ PBS (vehicle control) on days 0 and 2 and peritoneal cells and spleen were recovered at day 4 , according to published studies (17).

\section{RNA Isolation and qPCR}

Cells were washed twice with ice-cold PBS and lysed with RLT buffer. RNA was extracted by using the Aurum total RNA mini kit (Bio-Rad, San Diego, CA). cDNA was generated by iScript reverse transcriptase (Bio-Rad, San Diego, CA). RT-qPCR was performed with the Bio-Rad CFX Connect system using Bio-Rad CFX Manager 3.1 software. RELM $\alpha$ primers were purchased from Qiagen, Td Tomato primer sequence were (F: 5'-CCA CCT GTT CCT GGG GCA-3', R: 5'-ACT CTT TGA TGA CGG CCA TGT3'), and 18s primer sequences were (F: 5'-ACG GAA GGG CAC CAC CAG GA-3', R: 5'-CAC CAC CAC CCA CGG AAT CG-3’)

\section{Immunofluorescence}

Spleens were recovered and immediately immersed in 4\% PFA. After 24 hours, tissue was removed from 4\% PFA and incubated for 24 hours in $30 \%$ sucrose. For immunofluorescent staining, sections were incubated with rabbit anti-RELM $\alpha$ [2.5ug/ml; (Peprotech, Rock Hill, $\mathrm{NJ})$ ] or rabbit anti-TdTomato (Rockland Immunochemicals, Limerick, PA, USA), PE-anti CD3 (BioLegend, San Diego, CA) and FITC Rat anti-Foxp3 (eBioscience, Santa Clara, CA) overnight at $4^{\circ} \mathrm{C}$. Sections were incubated with Cy5 anti-Rabbit fluorochrome- 
conjugated antibodies for 2 hours at room temperature (Abcam, Cambridge, Ma), then counterstained with DAPI (BioLegend, San Diego, CA). FoxP3 ${ }^{+}$cells were quantified by the ImageJ software.

\section{Flow Cytometry and t-SNE Analysis}

Peritoneal cavity cells (PECs) were recovered in a total of $5 \mathrm{~mL}$ of ice-cold PBS. Splenic macrophage isolation were performed according to previous studies (33).Visceral fat was dissected and single cell dissociation and staining performed as previously described (34). For flow cytometry, cells were blocked with $0.6 \mu \mathrm{g}$ Rat IgG and $0.6 \mu \mathrm{g} \alpha$-CD16/32 (2.4G2) $5 \mathrm{~min}$, stained for $25 \mathrm{~min}$ with antibodies to CD11b (M1/70), MHCII (M5/114.15.2), CD11c (N418), CD4(RM4-5), Ly6C(HK 1.4), Ly6G(1A8), CD19(1D3) and CD8(53-6.7) (all from BioLegend, San Diego, CA); SiglecF (E50-2440) (BD Bioscience, San Jose, CA); F4/80 (BM8) (eBioscience, Santa Clara, CA). Cells were analyzed on a Novocyte (ACEA Biosciences, San Diego, CA) or LSRII instrument (BD Bioscience, San Jose, CA) followed by data analysis using FlowJo v10 (Tree Star Inc.; Ashland, OR). t-SNE analyses were performed with FlowJo v10, involving concatenation of samples (5000 cells per biological replicate) from all groups before running the t-SNE analyses to generate plots consistent between groups. This was followed by analysis of separated groups for expression of the desired markers. The parameters used to run the t-SNE analyses are in Supplementary Table 1. Arg, R $\alpha$ or TdTomato were excluded as parameters given that their expression was being analyzed, and they were negative in the some of the transgenic mouse groups.

\section{Cytokine Quantification}

For sandwich ELISA, capture and biotinylated detection antibodies were used according to previously described protocols (25). IL-23, IL- $1 \alpha$, IFN- $\gamma$, TNF- $\alpha$, MCP-1, IL-12p70, IL-1 $\beta$, IL-10, IL-6, IL-27, IL-17A, IFN- $\beta$ and GM-CSF were detected by the Mouse Inflammation Panel (13-plex) (BioLegend, San Diego, CA) and analyzed on the LSRII instrument (BD Bioscience) and LEGENDplex ${ }^{\mathrm{TM}}$ software.

\section{Splenocyte Stimulation}

Spleens were harvested from PBS or IL4c treated mice at day 4. Single cell suspensions were generated from whole spleen, and red blood cells lysed with ACK lysis buffer. Cells were stimulated in 48 well plates at $5 \times 10^{6}$ cells/well with $1 \mu \mathrm{g} / \mathrm{ml}$ of $\alpha$-CD3 and $\alpha$ CD28 (eBioscience) as described previously (29). Supernatants were recovered at day 3 for cytokine measurement.

\section{Macrophage and Splenocyte Co-Cultures}

Peritoneal cells from naïve $\mathrm{R} \alpha^{+/+}$or $\mathrm{R} \alpha^{\mathrm{Td} / \mathrm{Td}}$ mice were recovered and treated in vitro with IL-4 (20ng/ml) or equivalent control PBS in complete DMEM media (Invitrogen, Gaithersburg, MD). After 24hrs, supernatants were recovered for RELM $\alpha$ ELISA, cells were washed with PBS to remove non-adherent cells, followed by recovery of adherent macrophages with TrypLE ${ }^{\mathrm{TM}}$ Express (Invitrogen, Gaithersburg, MD) and plated in a 96-well flat bottom plate at $2 \times 10^{4}$ cells/well. In vivo-derived M2 macrophages were generated by one i.p. injection of IL-4c, recovery of the peritoneal cells, and F4/80 bead purification using MS columns with $>90 \%$ purity (Miltenyi Biotec, Inc). Splenocytes were recovered from naïve $\mathrm{R}^{+/+}$mice, and single cell suspensions prepared as above. Splenocytes were CFSE-labelled $(5 \mu \mathrm{M}, 15$ minutes) as previously described (29) (Invitrogen, Gaithersburg, MD), then added to the macrophages (Mac: Splenocyte $1: 10$ ) with $0.5 \mu \mathrm{g} / \mathrm{ml}$ $\alpha$-CD3 (5 replicate wells per condition). After 3 and 6 days, nonadherent splenocytes were recovered for flow cytometry analysis on the LSRII (BD Bioscience), and supernatants were recovered for cytokine measurement.

\section{Nanostring Gene Expression Analysis}

Peritoneal macrophages $\left(\mathrm{CD} 11 \mathrm{~b}^{+} \mathrm{F} 4 / 80^{+}\right)$were sorted with the MoFlo Astrios cell sorter (Beckman Coulter). 5000 macrophages from PBS mice or IL-4c-injected mice were lysed with $1 / 3$ RLT buffer diluted with $\mathrm{ddH}_{2} \mathrm{O}$ (Qiagen). Lysed cells were processed and quantified by the Myeloid Innate Immunity v2 panel according to manufacturer's instructions (Nanostring). Gene expression analysis was conducted using the Advanced Analysis Nanostring software. Raw counts were normalized to internal controls (4 housekeeping genes, Eef1g, Gusb, Oaz1 and Rpl19), then normalized transcripts with $\mathrm{n}>30$ counts were included for analysis (a total of 309 out of 734 genes). The Nanostring Advanced Analysis algorithm generated biological pathway scores by extracting pathway-level information from a group of genes using the first principal component (PC) of their expression data (35). Pathway scores of $\mathrm{R}^{+/+}$or $\mathrm{R} \alpha^{\mathrm{Td} / \mathrm{Td}}$ naive and IL-4c-injected mice were analyzed by an unpaired t-test and chosen pathways ( $\mathrm{p}$ value $\leq 0.05$ ) are represented as the difference in pathway score between the $\mathrm{R} \alpha^{+/+}$or $\mathrm{R} \alpha^{\mathrm{Td} / \mathrm{Td}}$ groups ( $\mathrm{n}=4$ /group). Differentially expressed (DE) genes $(\mathrm{p} \leq$ 0.05 ) in each pathway were graphed as heatmaps (36).

\section{Statistical Analysis}

Data are presented as mean \pm SEM and statistical analysis was performed by Graphpad Prism 9 software. Data was assessed by one-way ANOVA followed by post-hoc Tukey's test for multiple comparison, or by unpaired t-test for 2-group comparisons. For data collected over several time points, two-way ANOVA with postSidak multiple test was performed. ${ }^{\star}, \mathrm{p} \leq 0.05 ;{ }^{* *}, \mathrm{p} \leq 0.01$; ${ }^{\star * *}$, $\mathrm{p} \leq 0.001$. Experiments were repeated $2-4$ times with $\mathrm{n}=2-8$ per group for in vivo experiments, or 3-5 replicate wells for in vitro studies, apart from Nanostring gene expression analysis, which was performed once ( $n=2$ for naïve and $n=4$ for IL-4c injected per group).

\section{Mouse and Data Availability}

RELM $\alpha$ transgenic mice are available at MMRC repository (067014-UCD, https://mmrrc.ucdavis.edu).

\section{RESULTS}

\section{Generation and Validation of RELM $\alpha$ Transgenic Mice}

RELM $\alpha$ is a pleiotropic protein expressed by both immune and non-immune cells, and is detectable in the serum of naïve mice (16). In the serosal cavities, resident macrophages express 
RELM $\alpha$ in homeostatic conditions, however, RELM $\alpha$ expression is dramatically elevated in a type 2 cytokine environment such as helminth infection or IL-4c injection (17). We sought to address RELM $\alpha$ function in the peritoneal cavity by generating transgenic mice in which cre and flp recombinase mediates RELM $\alpha$ (exons 2-4) deletion and replacement with the TdTomato reporter protein (Figure 1A). To validate the targeting strategy and enable tracking of RELM $\alpha$-expressing cells, these founder mice were crossed to a universal cre deleter mouse line so that RELM $\alpha$ expression can be tracked by $\mathrm{Td}$ reporter protein in heterozygote mice $\left(\mathrm{R} \alpha^{\mathrm{Td} /+}\right)$, while homozygote mice $\left(\mathrm{R} \alpha^{\mathrm{Td} / \mathrm{Td}}\right)$ are used to investigate RELM $\alpha$ function. Quantification of RELM $\alpha$ protein in the serum and peritoneal cavity fluid indicated high levels of circulating RELM $\alpha$ under homeostatic conditions in $\mathrm{R}^{+/+}$mice, detectable but significantly reduced RELM $\alpha$ in heterozygote $\left(\mathrm{R} \alpha^{\mathrm{Td} /+}\right)$ mice, and no RELM $\alpha$ in homozygote mice $\left(\mathrm{R} \alpha^{\mathrm{Td} / \mathrm{Td}}\right)$ (Figure 1B). RELM $\alpha$ and $\mathrm{Td}$ mRNA levels were also quantified in adherent peritoneal cells from naive mice treated in vitro with IL-4 (Figure 1C). Both $\mathrm{R}^{+/+}$and $\mathrm{R} \alpha^{\mathrm{Td} /+}$ macrophages had equivalent IL-4 induced RELM $\alpha$ expression. In IL- 4 treated $\mathrm{R} \alpha^{\mathrm{Td} / \mathrm{Td}}$ and $\mathrm{R} \alpha^{\mathrm{Td} /+}$ macrophages, $\mathrm{Td}$ expression was increased. Although the $\mathrm{Td}$ expression pattern was similar to RELM $\alpha$ in the heterozygote mice, the fold induction of $\mathrm{Td}$ was much lower than that of RELM $\alpha$. This suggests differences in PCR efficiency, mRNA stability, or that deletion of RELM $\alpha$ has feedback consequences on the RELM $\alpha$ promoter and gene expression. We investigated if these potential differences in RNA levels were also observed at the protein level by flow cytometry. Intracellular RELM $\alpha$ and $\mathrm{Td}$ protein was evaluated by flow cytometry of peritoneal cells recovered from PBS or IL-4 complex (IL4c) injected mice (Figure 1D and Figure S1A). As expected, the main cellular sources of RELM $\alpha$ protein following IL4c injection were the small and large peritoneal macrophages (SPM and LPM) with $>95 \%$ expression of RELM $\alpha$ in $\mathrm{R}^{+/+}$and $\mathrm{R} \alpha^{\mathrm{Td} /+}$. In the $\mathrm{R} \alpha^{\mathrm{Td} /+}$ heterozygote mice, Td protein was induced by IL- 4 with $50 \%$ expression in LPM and $85 \%$ expression in SPM. We also observed IL-4c induced expression of RELM $\alpha$ and $\mathrm{Td}$ by eosinophils and $\mathrm{CD}^{+} \mathrm{B} 1$ cells (Figure 1D and Figure S1B). Finally, we examined RELM $\alpha$ and Td expression in other organs such as the visceral fat and the spleen (Figure S2A), where we observed some IL-4 induced RELM $\alpha$ or Td expression by macrophages, but this was much lower in magnitude compared to the peritoneal cells.

To evaluate heterogeneity in serosal macrophage populations, we generated t-SNE plots on flow cytometry data from IL-4ctreated Arginase-YFP/R $\alpha$ dual reporter mice (Figure 1E). The main subsets observed were LPM (red), SPM (blue) and B1 cells (cyan). When comparing heterozygote $\mathrm{R}^{\mathrm{Td} /+} \mathrm{Yarg}^{+/+}$and $\mathrm{R} \alpha^{\mathrm{Td} / \mathrm{Td}} \mathrm{Yarg}^{+/+}$, RELM $\alpha$ was expressed in SPM and LPM of heterozygote $\mathrm{R} \alpha^{\mathrm{Td} /+}$ but not in homozygote $\mathrm{R} \alpha^{\mathrm{Td} / \mathrm{Td}}$ mice. $\mathrm{R} \alpha^{\mathrm{Td} / \mathrm{Td}}$ mice showed instead Td protein expression with similar expression pattern to RELM $\alpha$. While SPM were a homogenous population with high level RELM $\alpha$ (or Td) expression, LPM exhibited more heterogeneity with mid and high level RELM $\alpha$ - expressing subsets (green vs yellow/red) (Figure 1F). In contrast, Arginase was more homogeneously expressed in both SPM and LPM (yellow/red). Together, these data validate effective RELM $\alpha$ deletion and replacement with TdTomato and indicate potential heterogeneity of RELM $\alpha$ compared to Arginase expression in the LPM. We also demonstrate that $\mathrm{R} \alpha^{\mathrm{Td} /+}$ heterozygote mice have robust Td and RELM $\alpha$ protein expression, supporting the utility of this transgenic mouse model to track RELM $\alpha$ expression.

\section{RELM $\alpha^{\mathrm{Td} / \mathrm{Td}}$ Mice Suffer From Increased IL-4c Induced Pathology}

Serosal macrophages that reside in the peritoneal cavity have important surveillance roles as sentinels for pathogen infections, but also regulate inflammation and can migrate to visceral organs to mediate repair (37). Peritoneal macrophages are main cellular sources with up to $100 \%$ RELM $\alpha$ expression following IL-4c injection, however, the function of RELM $\alpha$ in the peritoneal cavity has not been investigated. Wild-type $\left(\mathrm{R}^{+/+}\right)$or RELM $\alpha$ deficient $\left(\mathrm{R} \alpha^{\mathrm{Td} / \mathrm{Td}}\right)$ mice were injected with PBS or IL-4c. IL-4c injection led to significantly increased RELM $\alpha$ protein in the serum and RELM $\alpha$ mRNA in the peritoneal cells of $\mathrm{R}^{+/+}$mice, while Td mRNA was significantly elevated in peritoneal cells of $\mathrm{R} \alpha^{\mathrm{Td} / \mathrm{Td}}$ mice (Figure 2A). As previously reported (14), IL-4c caused increased peritoneal cell numbers in $\mathrm{R}^{+/+}$mice, but peritoneal inflammation was exacerbated in $\mathrm{R} \alpha^{\mathrm{Td} / \mathrm{Td}}$ mice (Figure 2B). Flow cytometric analysis revealed that LPM were the main cell-type affected by RELM $\alpha$ deficiency (Figure 2C). In the $\mathrm{R} \alpha^{+/+}$mice, peritoneal $\mathrm{B}$ cell numbers were significantly decreased by IL4c treatment (Figure 2C), and further subsetting into $\mathrm{CD}^{+} \mathrm{B} 1$ cells and $\mathrm{CD} 23^{+} \mathrm{B} 2$ cells revealed that the decrease was significant in B2 cells (Figure S2B). In contrast, neither B1 nor $\mathrm{B} 2$ cells were reduced by IL- $4 \mathrm{c}$ in $\mathrm{R} \alpha^{\tau \mathrm{d} / \mathrm{Td}}$ mice, and $\mathrm{B} 1$ cells were significantly higher in IL- $4 c$ treated $\mathrm{R} \alpha^{\mathrm{Td} / \mathrm{Td}}$ mice compared to IL$4 \mathrm{c}$ treated $\mathrm{R}^{+/+}$mice (Figure S2B), suggesting that RELM $\alpha$ is downstream of IL- $4 \mathrm{c}$ mediated reduction in $\mathrm{B}$ cells. Other peritoneal cell subsets were not affected by IL-4c treatment nor RELM $\alpha$ deficiency. IL-4c induces significant LPM proliferation, therefore we evaluated Ki67 expression as a marker for proliferation. There was a significant increase in Ki67 positive LPM and SPM in IL-4c injected $R \alpha^{\mathrm{Td} / \mathrm{Td}}$ mice but no changes in B cells (Figure 2D). RELM $\alpha$-deficient mice also exhibited IL-4 induced splenomegaly, which was more severe than observed in wild-type mice (Figures 2E, F). This suggested an exacerbated response in RELM $\alpha$ deficiency, similar to the macrophage activation syndrome caused by sustained IL-4 exposure (38). Proinflammatory cytokine measurement in the serum revealed that $\mathrm{R} \alpha^{\mathrm{Td} / \mathrm{Td}}$ mice had increased circulating cytokines compared to $\mathrm{R} \alpha^{+/+}$mice, with significant increases in IL1 $\alpha$ under homeostatic conditions, and increased TNF $\alpha$, IFN $\gamma$ and IL-6 following IL-4 treatment, but no changes in circulating type 2 cytokine IL-5 (Figure 2G). We also performed the same cytokine bead array analysis on peritoneal lavage fluid but did not observe detectable cytokine levels. Together, these data reveal that RELM $\alpha$ critically mitigates IL-4-induced inflammatory effects including LPM and SPM proliferation, splenomegaly and systemic proinflammatory cytokine expression. 

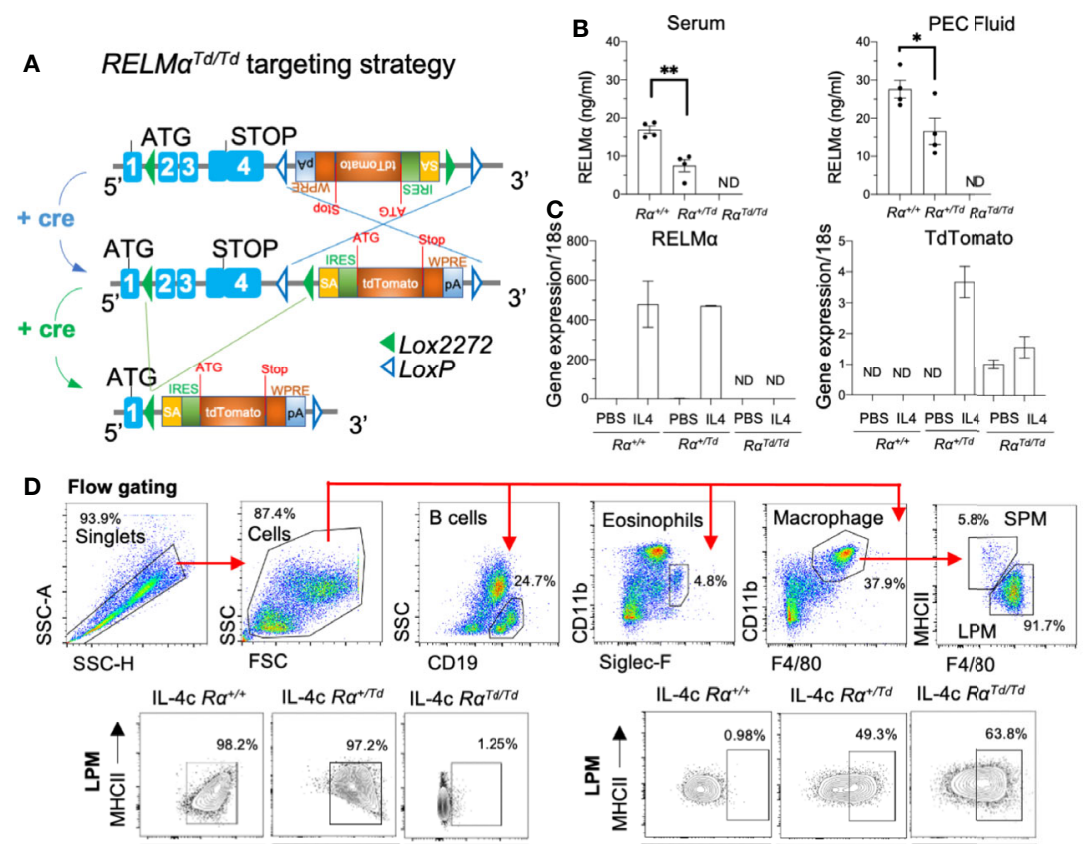

$\mathrm{IL}-4 \mathrm{c} R \alpha^{+/+} \quad \mathrm{IL}-4 \mathrm{c} R \alpha^{+/ T d} \quad \mathrm{IL}-4 \mathrm{c} R \alpha^{T d / T d}$
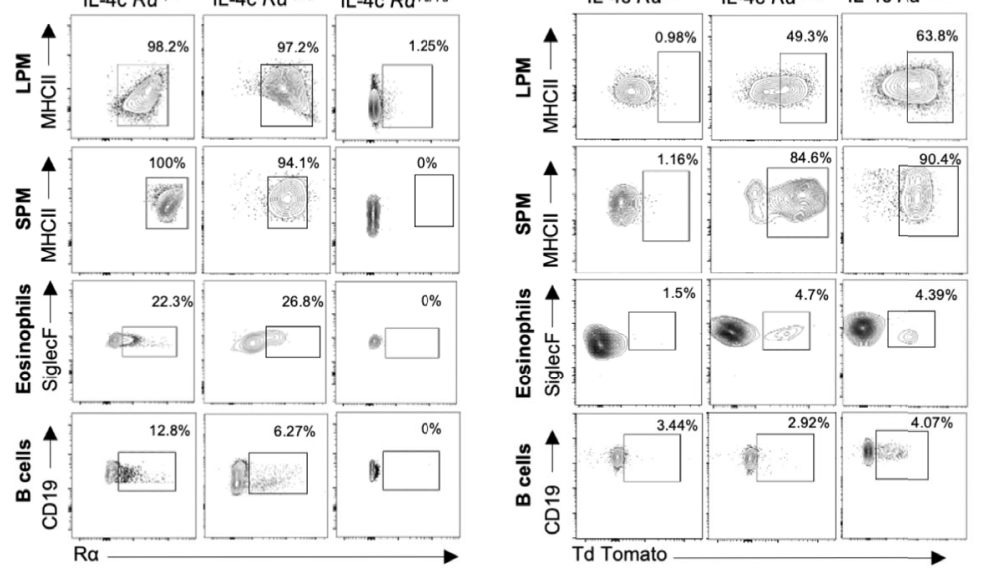

E
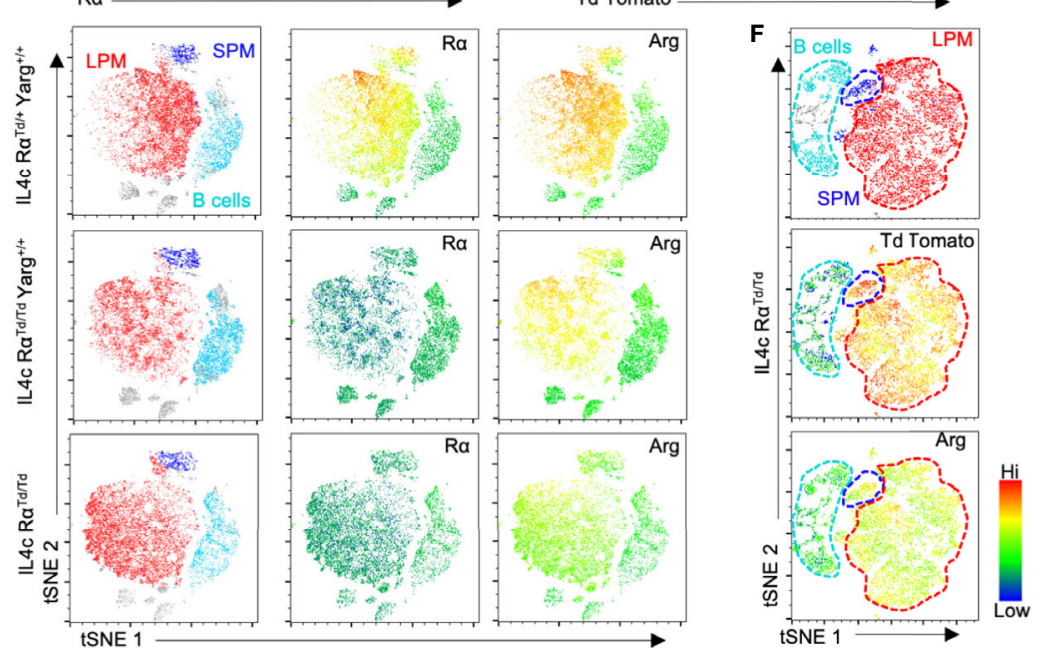

FIGURE 1 | Validation of RELM $\alpha$ reporter transgenic mice. RELM $\alpha(R \alpha)$ or TdTomato $(T d)$ reporter homozygote and heterozygote mice were intraperitoneally

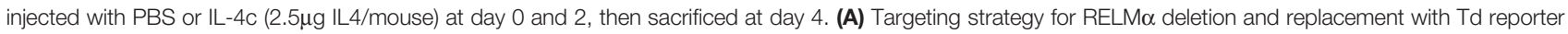
gene. (B) RELM $\alpha$ ELISA of serum and peritoneal fluid of 6-8 weeks mice. (C) RELM $\alpha$ and Td qRT-PCR of peritoneal cells treated in vitro for 24h with IL-4 (20ng/ml), presented as relative expression to PBS and normalized to 18 s transcript. R $\alpha$ expression was normalized to the PBS R $\alpha^{+/+}$group (set at "1") (D) Flow cytometry gating and analysis of large and small peritoneal cells (LPM and SPM), eosinophils and B cells from IL4c-injected mice for Td and RELM $\alpha$ protein. (E, F) t-SNE -guided analysis of peritoneal cavity cells subsets gated according to 1D (LPM, red; SPM, blue; B1 cell, cyan) for expression of Ro, Arg ${ }^{\text {YFP }}$ and Td employing R $\alpha^{\text {Td }}$ and Yarg reporter mice. Results shown are combined from 2-3 independent experiments ( $n=4-12)$, apart from (C, E) which is one experiment, $n=3$ replicates. ND, not detected. ${ }^{*}, \mathrm{p} \leq 0.05 ;{ }^{* *}, \mathrm{p} \leq 0.01$. 

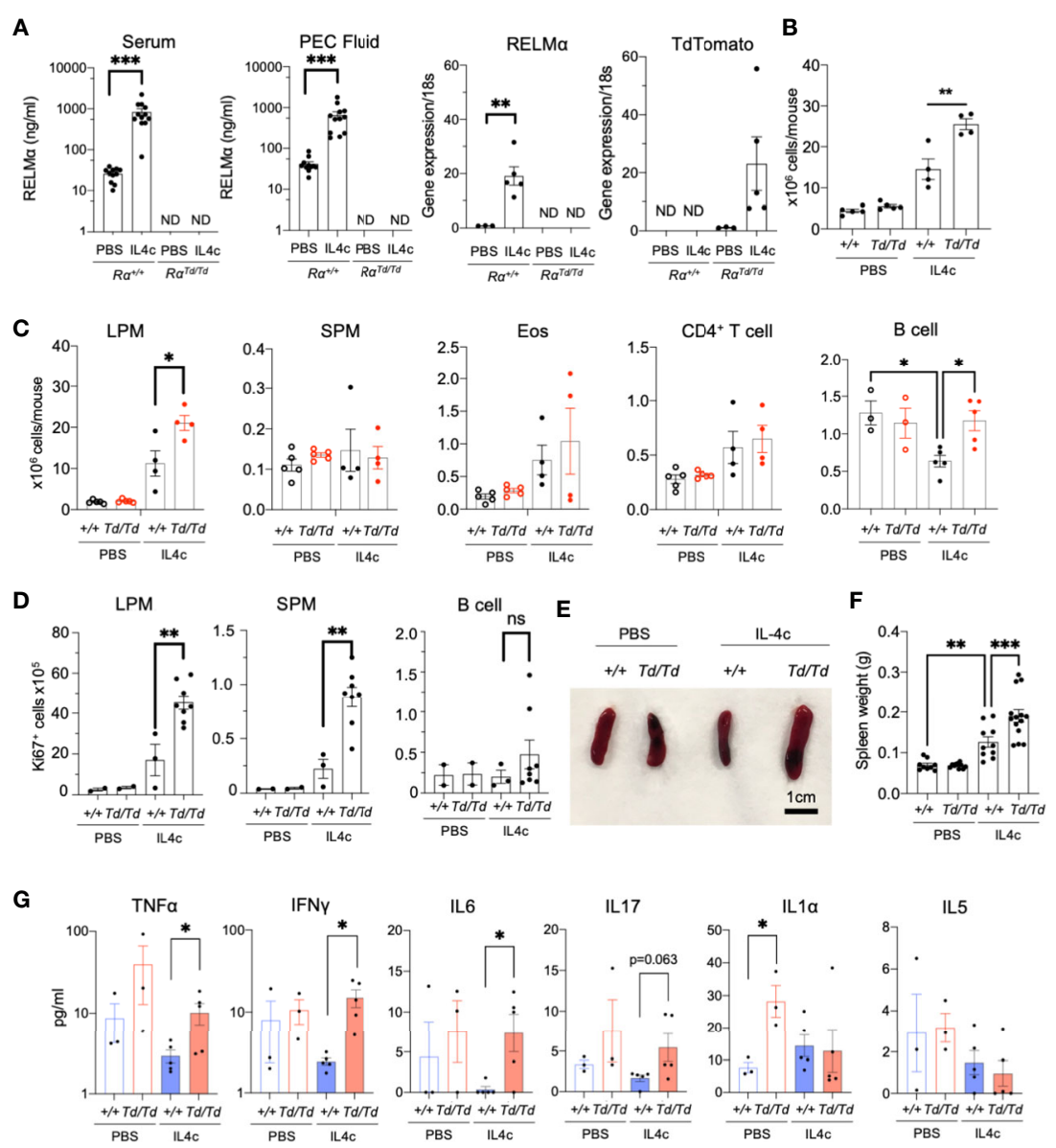

FIGURE 2 | Increased IL-4-induced pathology in RELM $\alpha^{\text {Td/Td }}$ mice. PBS or IL4c-injected R $\alpha^{+/+}$or $R \alpha^{\text {Td/Td }}$ mice were sacrificed at day 4 followed by evaluation of spleen and peritoneal cavity responses. (A) Peritoneal fluid and serum RELM $\alpha$ levels measured by ELISA, and RELM $\alpha$ and Td RNA was measured by peritoneal cell qRT-PCR as relative expression to PBS and normalized to 18 s transcript. R $\alpha$ expression was normalized to the PBS R $\alpha^{+/+}$group (set at "1") (B, C) Peritoneal inflammation and subset frequency evaluated by cell counts and flow cytometry analysis for small and large peritoneal macrophages (SPM and LPM), eosinophils, $\mathrm{CD}^{+} \mathrm{T}$ cells and B cells. (D) Peritoneal cell proliferation assessed by Ki67 staining. (E, F) Spleen size and weight were measured. (G) Serum cytokines were quantified. Results shown are representative of 3 independent experiments ( $n=4-8$ per group). ND, not detected. ${ }^{*}, p \leq 0.05 ;{ }^{* *}, p \leq 0.01 ;{ }^{* \star *}, p \leq 0.001$.

\section{RELM $\alpha$ Deficiency Leads to Dysregulated IL-4 Induced Myeloid Gene Expression Associated With T Cell Response, Growth Factor and Cytokine Signaling, and Myeloid Differentiation}

To identify mechanisms underlying RELM $\alpha$ regulation of peritoneal macrophage responses, gene expression analysis was performed in $\mathrm{F} 4 / 80^{+} \mathrm{CD} 11 \mathrm{~b}^{+}$peritoneal macrophages sorted from PBS or IL-4c treated $\mathrm{R}^{+/+}$or $\mathrm{R} \alpha^{\mathrm{Td} / \mathrm{Td}}$ mice, using the Nanostring myeloid immunity panel (734 genes) (Figure 3A). Principal component analysis (PCA) demonstrated clustering according to genotype and treatment, with IL-4 treatment driving the greatest transcriptional differences regardless of genotype (Figure 3B). Out of four mice, macrophages from one IL-4c-treated $\mathrm{R}^{+/+}$mice appeared as an outlier and clustered with the PBS-treated group (Figure 3B, red circle). Retrospective analysis revealed that this mouse had less RELM $\alpha$ in the PEC fluid, and lower peritoneal cell numbers likely because of ineffective IL-4c delivery (Figure S3A), therefore this sample was removed from gene expression analyses.

Investigation of the most differentially expressed genes indicated that Chil3/4 (Ym1/Ym2) and Rnase2a (Ear11) were highly upregulated by IL-4 for both mouse genotypes (Figures 3C, D). As signature M2 macrophage genes, RELM $\alpha$ and $\mathrm{Ym} 1 / 2$ are reported to have equivalent expression patterns, but Ym1 can also promote RELM $\alpha$ expression (24). Ear11 is an eosinophil-associated ribonuclease that is secreted by M2 macrophages and promotes neutrophil chemotaxis (39). Consistent with IL-4 induced resident macrophage proliferation, genes associated with the cell cycle (Top2a, Cdc20, Kif20a, Ccnb2) were upregulated. Consistent with an anti-inflammatory function for M2 macrophages, both $\mathrm{R} \alpha^{+/+}$ and $\mathrm{R} \alpha^{\mathrm{Td} / \mathrm{Td}}$ macrophages from IL-4c treated mice had reduced expression of genes associated with chemotaxis (Cxcl13, Cxcl14, 

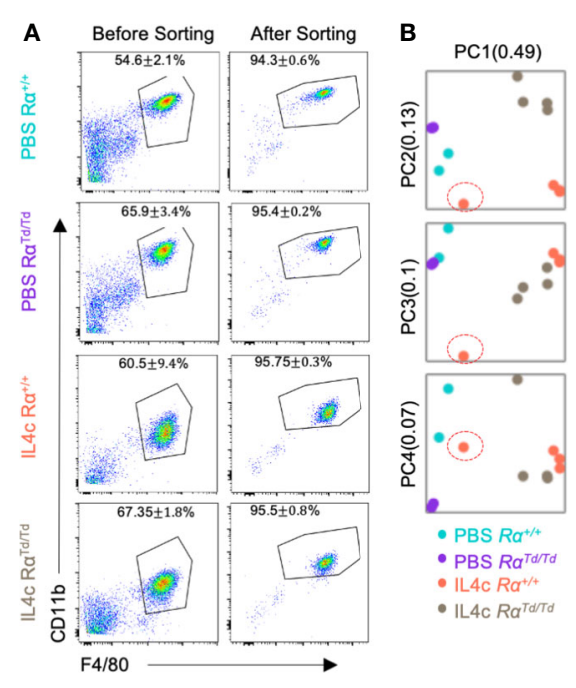
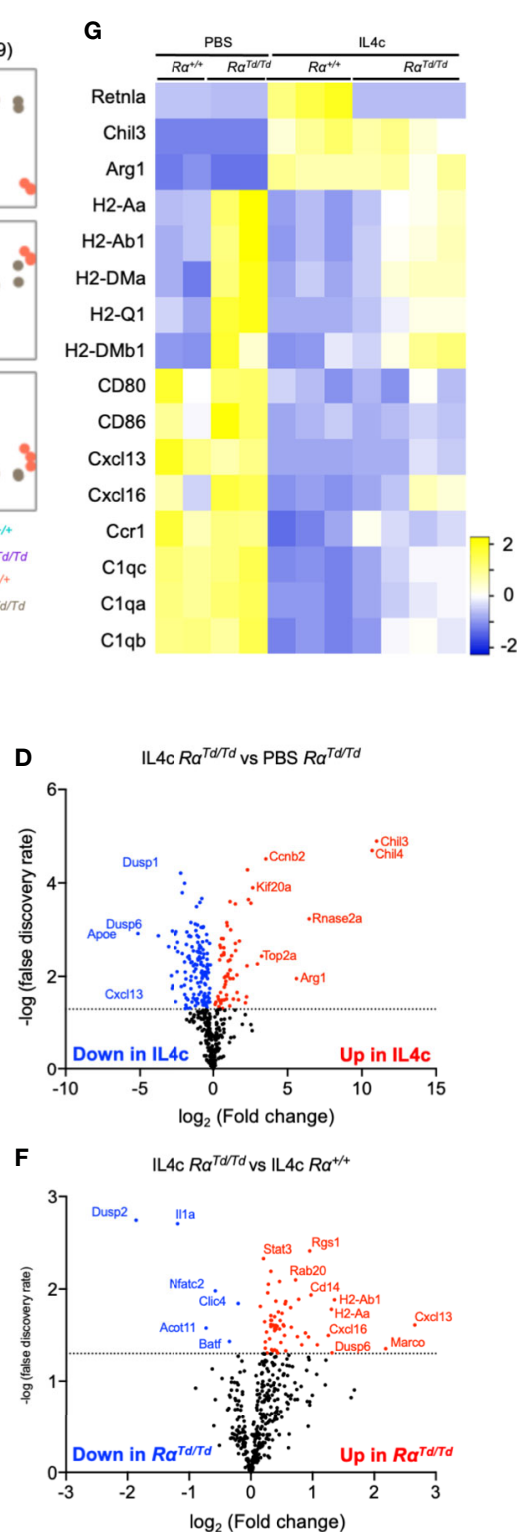
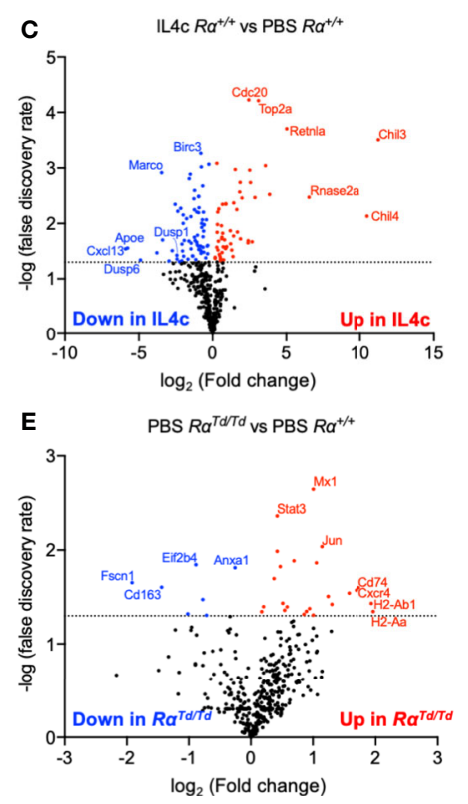

FIGURE 3 | Gene expression analysis of peritoneal macrophages identify IL-4-induced and suppressed genes that are regulated by RELM $\alpha$. Peritoneal macrophages were sorted from PBS or IL4c-injected $\mathrm{R} \alpha^{+/+}$or $\mathrm{R} \alpha^{\mathrm{Td} / \mathrm{Td}}$ mice and analyzed by using the Nanostring myeloid gene expression panel. (A) Flow cytometry gating strategy and purity. (B) Principal component analysis demonstrates sample clustering. (C-F) Volcano plot of genes that are most changed in response based on IL-4c treatment (C, D) or genotype (E, F). (G) Heatmap of canonical macrophage activation genes in different groups. Nanostring gene expression data are from a single experiment ( $\mathrm{n}=2$ for PBS and $\mathrm{n}=4$ for $\mathrm{IL}-4 \mathrm{c}$ injected).

Cxcl2), complement responses (C1qa, C1qb, C1qc) and innate immune activation (Birc3, CD80, CD86) (Figures 3C, D, G). Unexpectedly, the dual-specificity protein phosphatases (Dusp1, Dusp6), and Apoe were also suppressed by IL-4, although these have proposed anti-inflammatory and repair functions (40). These expression patterns likely reflect in vivo macrophage plasticity and the unique response of resident peritoneal macrophages to repeated treatment with IL-4, which may lead to negative feedback pathways for type 2 cytokine signaling. Overall, these genes were similarly induced or suppressed by IL- 4 in both $\mathrm{R}^{+/+}$and $\mathrm{R} \alpha^{\mathrm{Td} / \mathrm{Td}}$ mice, suggesting that these resident M2 macrophage activation programs occur even in the absence of RELM $\alpha$.

We next evaluated RELM $\alpha$-regulated genes (Figures 3E-G). The most consistently upregulated genes in PBS or IL-4-induced $\mathrm{R} \alpha^{\mathrm{Td} / \mathrm{Td}}$ macrophages were MHC class II genes associated with antigen presentation ( $\mathrm{H} 2$ genes, CD74), suggesting enhanced antigen presentation function by macrophages in RELM $\alpha$ deficient mice even in homeostatic conditions. RELM $\alpha$ deficient macrophages also had increased expression of 
chemokine/chemokine receptors (Ccl6, Cxcl13, Cxcl16) (Figure 4A). Cxcl13, involved in B1 cell maintenance (41), was the most upregulated gene in IL-4c induced $\mathrm{R} \alpha^{\mathrm{Td} / \mathrm{Td}}$ macrophages compared to $\mathrm{R}^{+/+}$macrophages, consistent with the increased B1 cell numbers in RELM $\alpha$-deficient mice. Conversely Dusp2, which negatively regulates cell proliferation $(42,43)$, was the most downregulated in the $\mathrm{R} \alpha^{\mathrm{Td} / \mathrm{Td}}$ macrophages (Figure 4A), consistent with their enhanced proliferation. Advanced pathway analysis (35) was performed to determine functional pathways that were significantly altered by RELM $\alpha$ following IL-4 treatment (Figure 4B). Consistent with upregulation of genes associated with macrophage hyperactivation, functional pathways that were significantly induced in RELM $\alpha$-deficient macrophages involved enhanced $\mathrm{T}$ cell responses (Th1 activation, $\mathrm{T}$-cell activation, antigen presentation). RELM $\alpha$-deficient macrophages also induced genes associated with cytokine and growth factor signaling (Pdgfb, Jak3, Syk), which may have contributed to their increased expansion in response to IL-4 (Figure 4C). This increased macrophage proliferation and frequency in $\mathrm{R} \alpha^{\mathrm{Td} / \mathrm{Td}}$ mice may therefore result from dual effects of increased growth factor expression and responsiveness, and decreased expression of downregulatory checkpoints, such as Dusp2 and Batf (Figure 4C). $\mathrm{R} \alpha^{\mathrm{Td} / \mathrm{Td}}$ macrophages showed a reduction in genes associated with differentiation of myeloid cells (Mafb, Cebpa, Laptm5), which may reflect the enhanced proliferation rather than differentiation or maturation of these macrophages in the absence of RELM $\alpha$.

Genes associated with angiogenesis (Fn1, Pdgfb) (44), phagocytosis (MerTK, Timd4, MHCII, C1q, CD16/32, Rab20 and Anxa1) (45-47), and the scavenger receptors (Marco, CD163) were increased in $\mathrm{R} \alpha^{\mathrm{Td} / \mathrm{Td}}$ macrophages (Figure 4C).
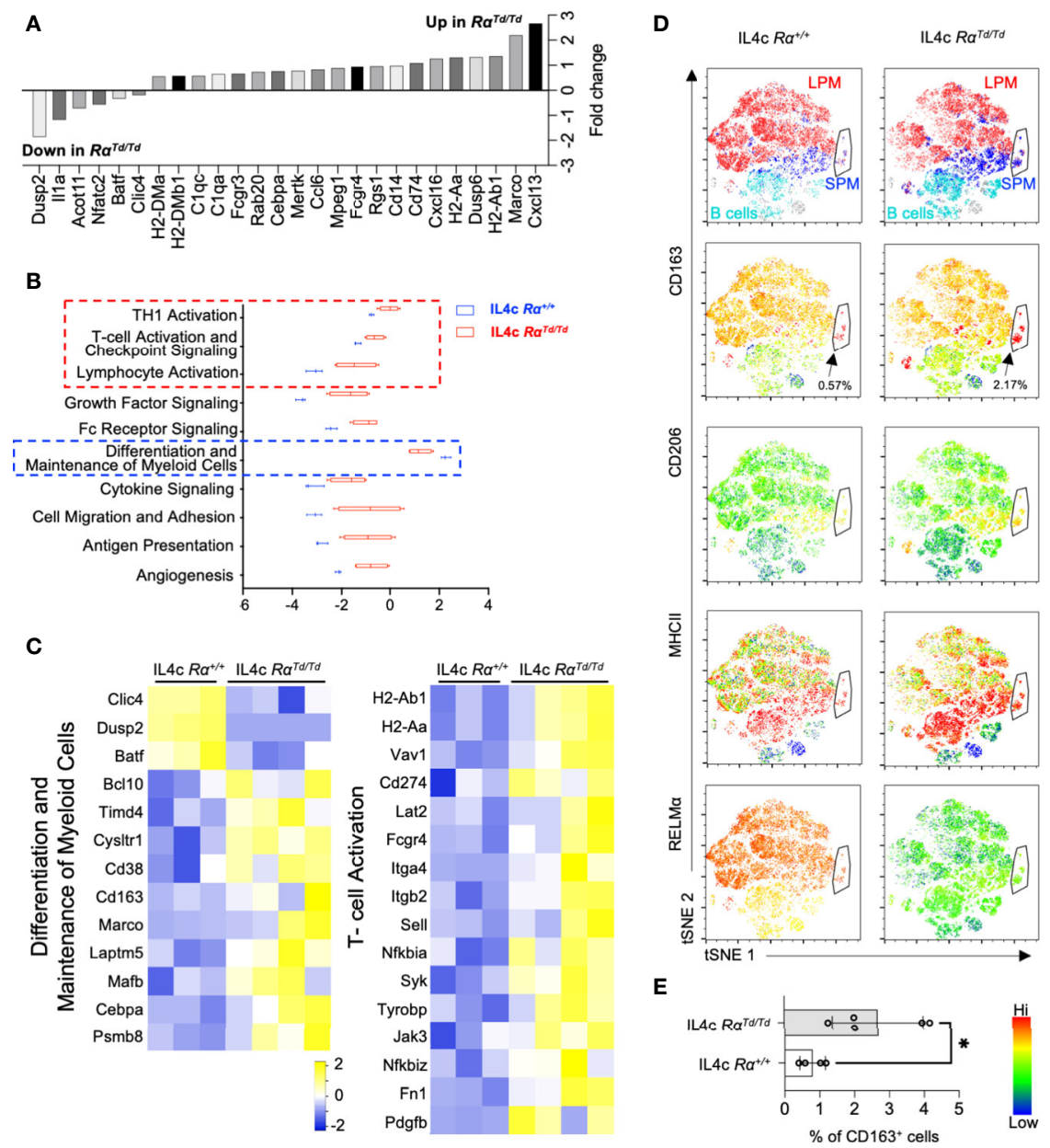

FIGURE 4 | RELM $\alpha$-deficient M2 macrophages exhibit a hyperactivated macrophage phenotype. Differential expression of genes associated with functional pathways was evaluated in macrophages sorted from IL-4c injected $R \alpha^{+/+}$or $R \alpha^{T d / T d}$ mice. (A) Genes with highest Log2 fold change differences between IL4c injected $R \alpha^{+/+}$and IL4c $R \alpha^{\text {Td/Td }}$ identified by Nanostring advanced analysis $(\mathrm{p}<0.05)$. (B) Advanced pathway analysis performed on IL4c R $\alpha^{+/+}$and IL4c $R \alpha^{\text {Td } / T d}$ macrophage RNA reveals significantly increased or decreased pathway scores $(p<0.05)$. (C) Heatmap of differentially expressed genes within the functional pathways. (D) t-SNE-guided flow cytometry analysis of peritoneal cell subsets (LPM, red; SPM, blue; B1 cell, cyan). Black arrow and outline indicate a separate subset with SPM and LPM characteristics. Subsets were evaluated for expression of CD163, CD206, MHCIl and RELM $\alpha$. (E) Frequency of CD163 ${ }^{+}$macrophages in IL4c-treated $R \alpha^{+/+}$and $R \alpha^{T d / T d}$ mice. ${ }^{*}, \mathrm{p} \leq 0.05$. 
This was consistent with the IL- 4 treated $\mathrm{R} \alpha^{\mathrm{Td} / \mathrm{Td}}$ mice exhibiting characteristics of macrophage activation syndrome, associated with splenomegaly and erythrophagocytosis (38). To further analyze and validate some of these genes and their association with RELM $\alpha$ at the single cell and protein level, we use t-SNE mapping of flow cytometry data of peritoneal cells (Figure 4D). The t-SNE plots indicated the presence of a small subset that shared SPM and LPM characteristics (black arrow). This subset had the highest expression of CD163 and MHC class II, and coexpressed RELM $\alpha$ in the $\mathrm{R}^{+/+}$mice. Further, it was increased by four-fold in the $\mathrm{R} \alpha^{\mathrm{Td} / \mathrm{Td}}$ mice, suggesting that RELM $\alpha$ expression by this subset may provide an autocrine negative feedback to limit its own expansion. Consistent with the Nanostring data, the MHCII ${ }^{\text {hi }}$ expressing subsets (Figure 4D, red) were expanded in the $\mathrm{R} \alpha^{\mathrm{Td} / \mathrm{Td}}$ macrophages, especially in the SPM and SPM->LPM subsets, consistent with the significantly increased MHCII MFI in SPM but not LPM in $\mathrm{R}^{\mathrm{Td} / \mathrm{Td}}$ mice (Figure S2C). however, there was heterogeneous distribution in LPM reflecting two functionally distinct LPM subsets in response to IL-4. Anti-CD163 surface staining confirmed the Nanostring data that $\mathrm{R} \alpha^{\mathrm{Td} / \mathrm{Td}}$ macrophages had significantly elevated CD163 expression in the SPM, LPM and the SPM to LPM cell subset, and was co-expressed with the M2 macrophage marker CD206 (Figure 4D). CD163 is a scavenger receptor for hemoglobin and is increased in M2 macrophages associated with hemophagocytic syndromes (48). Combined with the increased expression of genes associated with phagocytosis and scavenger functions, our observations that $\mathrm{CD}_{163^{+}} \mathrm{M} 2$ macrophages are significantly expanded in $\mathrm{R} \alpha^{\mathrm{Td} / \mathrm{Td}}$ mice (Figure 4E) point to a causal link between enhanced macrophage scavenging and the exacerbated IL- 4 induced inflammation and splenomegaly in $\mathrm{R} \alpha^{\mathrm{Td} / \mathrm{Td}}$ mice $(38,49-51)$.

\section{RELM $\alpha$-Expressing M2 Macrophages Support Regulatory T Cell Responses}

Our in vivo data suggests that RELM $\alpha$ mice suffer from increased proinflammatory cytokine expression that is associated with enhanced macrophage activation, including increased expression of genes involved in $\mathrm{T}$ cell activation. We therefore investigated if macrophage-intrinsic RELM $\alpha$ dampens proinflammatory $\mathrm{T}$ cell responses using in vitro co-culture of peritoneal macrophages with splenocytes. Resident peritoneal macrophages from naive $\mathrm{R} \alpha^{+/+}$or $\mathrm{R} \alpha^{\mathrm{Td} / \mathrm{Td}}$ mice were recovered and activated in vitro with IL-4, leading to significant RELM $\alpha$ secretion by $\mathrm{R}^{+/+}$macrophages (Figure 5A). The macrophages were then recovered and co-cultured with CFSE-labeled splenocytes activated with anti-CD3. After 3 days of co-culture, only modest proliferation of effector CD4 T cells $\left(\mathrm{CD} 4^{+} \mathrm{CD} 25^{-}\right)$ was observed $(\sim 15 \%)$ (Figures 5B, C), although robust proliferation was observed by day $6(\sim 70 \%)$ (Figure S3C). Although there were no differences in effector $\mathrm{T}$ cell proliferation, $\mathrm{CD} 4{ }^{+} \mathrm{CD} 25^{+} \mathrm{Foxp}^{+}$regulatory $\mathrm{T}$ cells (Treg) exhibited robust proliferation (60-80\%), which was significantly higher when co-cultured with IL-4 treated $\mathrm{R}^{+/+}$ macrophages compared to PBS treated $\mathrm{R}^{+/+}$macrophages (Figure 5D). PBS-treated $\mathrm{R} \alpha^{\mathrm{Td} / \mathrm{Td}}$ macrophages supported equivalent Treg proliferation compared to PBS $\mathrm{R}^{+/+}$ macrophages, however IL-4 treated $\mathrm{R} \alpha^{\mathrm{Td} / \mathrm{Td}}$ macrophages were unable to enhance Treg proliferation (Figure 5D).

We evaluated the downstream effects of macrophage-Treg interaction by quantifying cytokine secretion. Macrophages or splenocytes cultured alone did not produce cytokines (Figure 5E and data not shown). Both PBS or IL-4 treated $\mathrm{R}^{+/+}$macrophagessplenocyte co-cultures resulted in robust and equivalent secretion of IL-10, GM-CSF, and IFN $\gamma$, while IL-4-treated macrophages promoted enhanced secretion of IL-1 $\alpha$, MCP-1, IL-6. Co-cultures with PBS-treated $\mathrm{R} \alpha^{\mathrm{Td} / \mathrm{Td}}$ macrophages induced equivalent cytokine secretion to PBS-treated $\mathrm{R}^{+/+}$macrophages, however, IL-4-treated $\mathrm{R} \alpha^{\mathrm{Td} / \mathrm{Td}}$ macrophages were unable to promote cytokines associated with Treg differentiation and function (IL-10 and GM-CSF). Instead, IL-4-treated $\mathrm{R} \alpha^{\mathrm{Td} / \mathrm{Td}}$ macrophages promoted secretion of MCP-1, IL-6. We also observed a reduction in IFN $\gamma$ and IL- $1 \alpha$ secretion in co-cultures with IL- 4 treated $\mathrm{R} \alpha^{\mathrm{Td} / \mathrm{Td}}$ macrophages. Given that the co-cultures consisted of macrophages and splenocytes, the cellular source of the cytokines is unclear. Since the splenocytes are treated with anti-CD3, we conclude that most of the cytokines detected are directly from $\mathrm{T}$ cells, or indirectly from $\mathrm{T}$ cells activating other splenocytes or the peritoneal macrophages to produce cytokines.

We also investigated in vivo-derived M2 macrophages by IL-4c intraperitoneal injection, followed by recovery and purification of $\mathrm{F} 4 / 80^{+}$macrophages at day 1 , and co-culture with anti-CD3 stimulated splenocytes (Figure 5F). Similar to the in vitro-derived M2 macrophages, co-culture with $\mathrm{R} \alpha^{\mathrm{Td} / \mathrm{Td}}$ macrophages led to significantly reduced Treg proliferation compared to $\mathrm{R} \alpha^{+/+}$ macrophages, with no significant effect on effector $\mathrm{T}$ cells. The $\mathrm{R} \alpha^{\mathrm{Td} / \mathrm{Td}}$ co-cultures also had significantly reduced IL-2 levels compared with the $\mathrm{R}^{+/+}$macrophage co-cultures (Figure 5G), which may explain the reduced Treg proliferation. Together, this data suggests that macrophage-derived RELM $\alpha$ promotes Treg responses and suppresses myeloid expression of chemokines and proinflammatory cytokines, but has a mixed effect on $\mathrm{T}$ cell polarization and inflammasome activation.

\section{Dysregulated Splenic T Cell Responses and Reduced Regulatory T Cells in RELM $\alpha$-Deficient Mice}

Based on the co-culture results that demonstrated a direct effect of macrophage-derived RELM $\alpha$ in supporting Treg responses, we sought to determine the in vivo relevance of this novel regulatory function for RELM $\alpha$. We therefore evaluated peritoneal macrophage and splenic T cell responses in PBS or IL-4c-treated $\mathrm{R} \alpha^{+/+}$or $\mathrm{R} \alpha^{\mathrm{Td} / \mathrm{Td}}$ mice. We observed significantly increased CD25 expression in the $\mathrm{R} \alpha^{\mathrm{Td} / \mathrm{Td}} \mathrm{LPM}$ and SPM (Figure 6A), which may provide one mechanism for limiting IL-2 availability to Tregs (52). t-SNE mapping showed that most IL-4c induced $\mathrm{R} \alpha^{\mathrm{Td} / \mathrm{Td}} \mathrm{SPM}$ and a small subset of $\mathrm{R} \alpha^{\mathrm{Td} / \mathrm{Td}} \mathrm{LPM}$ expressed CD25, compared to low expression in IL-4c induced $\mathrm{R}^{+/+}$macrophages (Figure 6B). To validate the in vitro finding of impaired Treg responses in the absence of RELM $\alpha$, we quantified Treg frequencies in the spleens of PBS or IL-4c-treated $\mathrm{R}^{+/+}$and $\mathrm{R} \alpha^{\mathrm{Td} / \mathrm{Td}}$ mice. Immunofluorescent analysis of the periarteriolar lymphoid sheath of the spleen confirmed that IL4c-treated $\mathrm{R} \alpha^{\mathrm{Td} / \mathrm{Td}}$ mice had significantly reduced Foxp $3^{+}$cells (Figures 6C, D). Additionally, IL-4c 
A

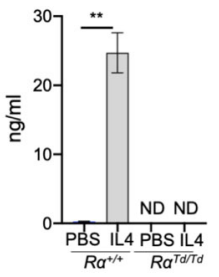

C

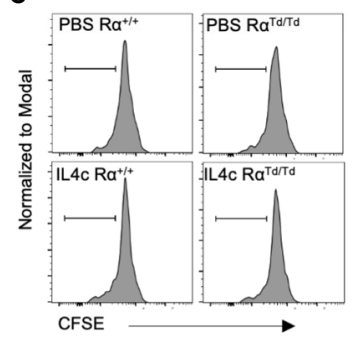

B Gating of $\mathrm{CD} 4^{+} \mathrm{CD} 25^{+} \mathrm{Foxp} 3^{+}$Treg cells
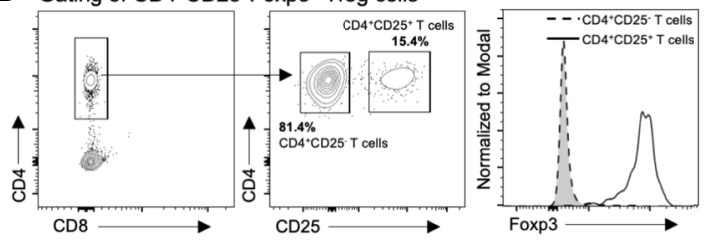

D

E
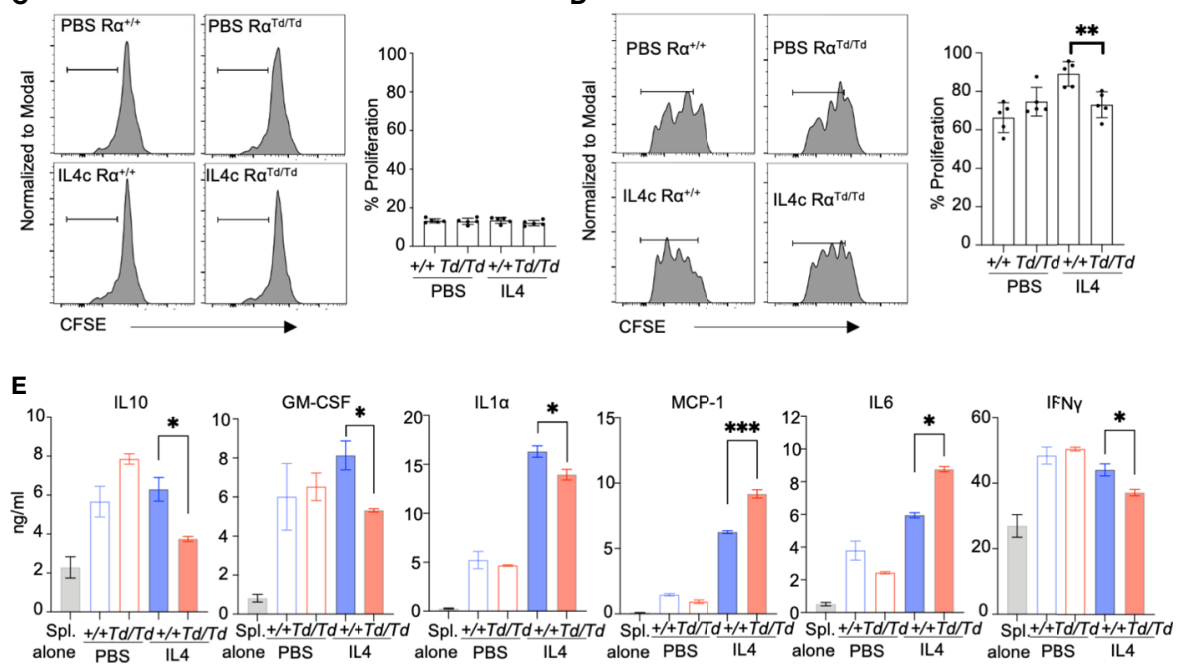

$\mathbf{F}$
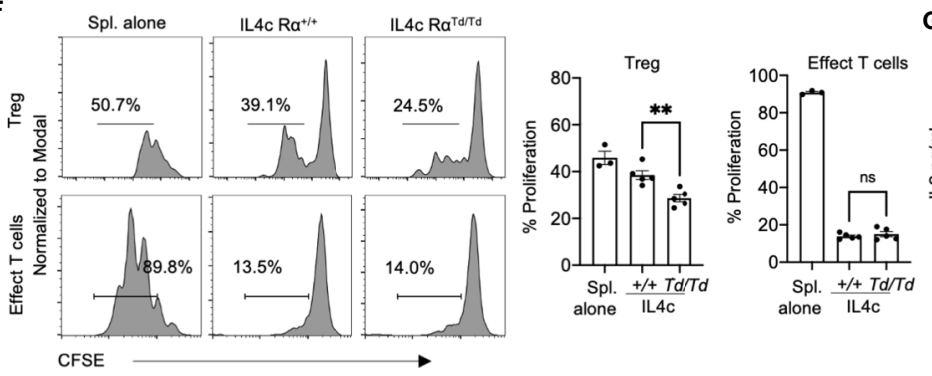

G

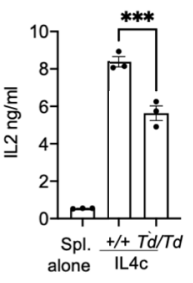

FIGURE 5 | Macrophage-derived RELM $\alpha$ promotes regulatory T cell responses. Peritoneal macrophages from R $\alpha^{+/+}$or R $\alpha^{T d / T d}$ mice were treated with PBS or IL-4 (20ng/mL) for 24h, washed then adherent macrophages were co-cultured for three days with CFSE-labeled splenocytes with anti-CD3 at a 1:10 (Mac : Splen ratio). (A) RELM $\alpha$ secretion by peritoneal macrophages treated in vitro with PBS or activated with IL-4. (B) T cell gating strategy. (C, D) Proliferation of CD4+CD25 ${ }^{-} \mathrm{T}$ cells (C) and $\mathrm{CD}^{+} \mathrm{CD} 25^{+}$FoxP3 ${ }^{+}$Tregs (D) when splenocytes are co-cultured with peritoneal macrophages treated in vitro with PBS or IL4 (E) Cytokine secretion measured at day 3 post-culture. (F) Proliferation of $\mathrm{CD}^{+} \mathrm{CD} 25^{-} \mathrm{T}$ cells and $\mathrm{CD} 4^{+} \mathrm{CD} 25^{+} \mathrm{FoxP} 3^{+}$Tregs when splenocytes are co-cultured with $\mathrm{F} 4 / 80+$ peritoneal macrophages purified from in vivo IL-4c-treated mice. (G) IL-2 secretion measured at day 3 post-culture. ND, not detected; NS, not significant. *, $p \leq 0.05$; ${ }^{\star *}, \mathrm{p} \leq 0.01 ;{ }^{* \star *}, \mathrm{p} \leq 0.001$.

treatment led to detectable RELM $\alpha$ protein expression in $\mathrm{R}^{+/+}$ mice and Td protein in $\mathrm{R} \alpha^{\mathrm{Td} / \mathrm{Td}}$ mice (Figure 6C), suggesting local effects of RELM $\alpha$ on the spleen. Flow cytometry analysis of the spleen also revealed significant reductions in $\mathrm{CD} 44^{+} \mathrm{CD} 25^{+}$Tregs in IL4c-treated $\mathrm{R} \alpha^{\mathrm{Td} / \mathrm{Td}}$ mice compared to $\mathrm{R} \alpha^{+/+}$mice (Figures $6 \mathrm{E}, \mathbf{F}$ ).

We next evaluated if the Treg deficiency in $\mathrm{R} \alpha^{\mathrm{Td} / \mathrm{Td}}$ mice was associated with dysregulated $\mathrm{T}$ cell polarization in the spleen. AntiCD3 stimulation of splenocytes from IL-4c-treated $\mathrm{R} \alpha^{\mathrm{Td} / \mathrm{Td}}$ mice led to significantly increased secretion of IL-17A, TNF $\alpha$ and IL- $1 \alpha$ compared to splenocytes from the counterpart $\mathrm{R} \alpha^{+/+}$mice (Figure 6G). Combined, these in vitro and in vivo data reveal a previously unappreciated role for peritoneal macrophage-derived RELM $\alpha$ in mitigating IL-4 induced inflammation and immunopathology through promoting Treg responses and limiting proinflammatory macrophage and $\mathrm{T}$ cell responses.

\section{DISCUSSION}

As critical sentinels of the peritoneal cavity and visceral organs, the biology of peritoneal macrophages is increasingly being investigated $(2,53-56)$. These studies highlight the complexity and importance 
A
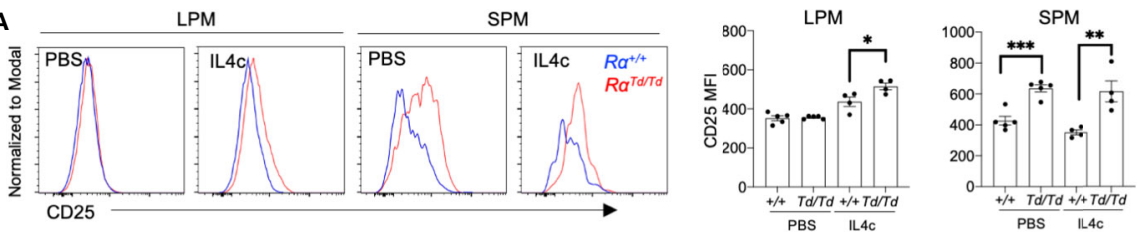

B
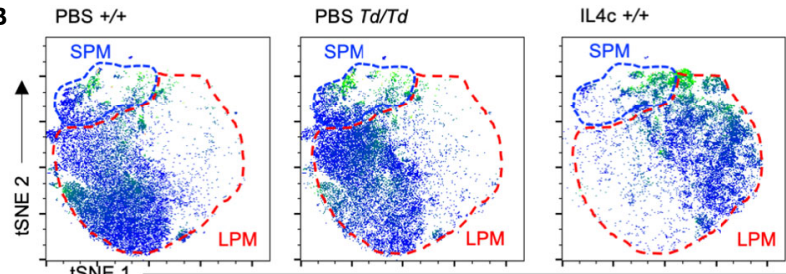

IL4c $T d / T d$
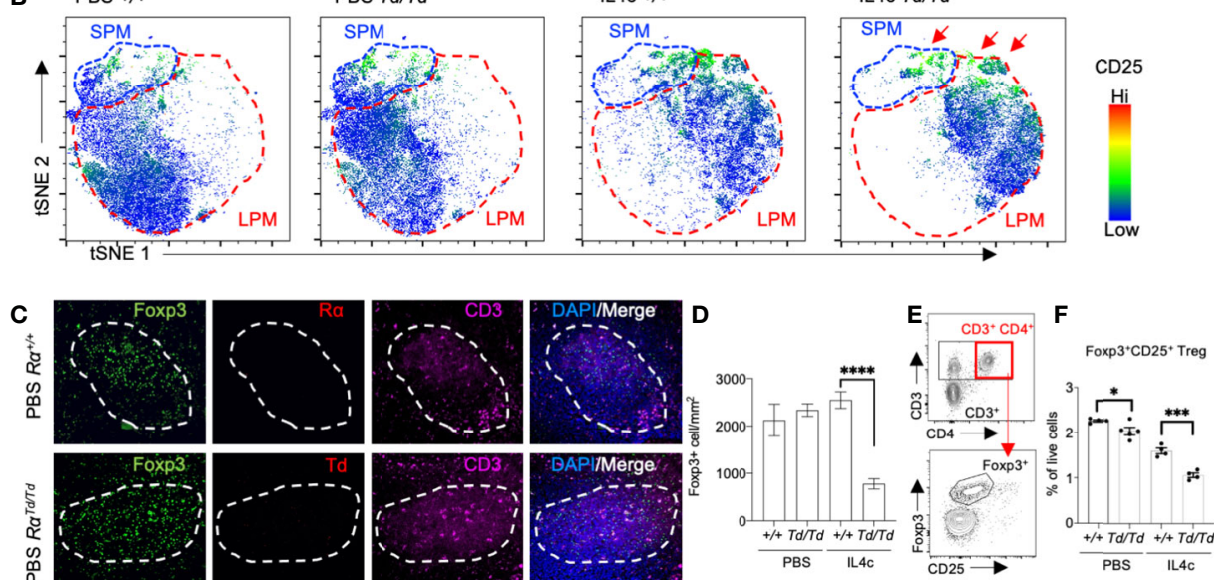

G
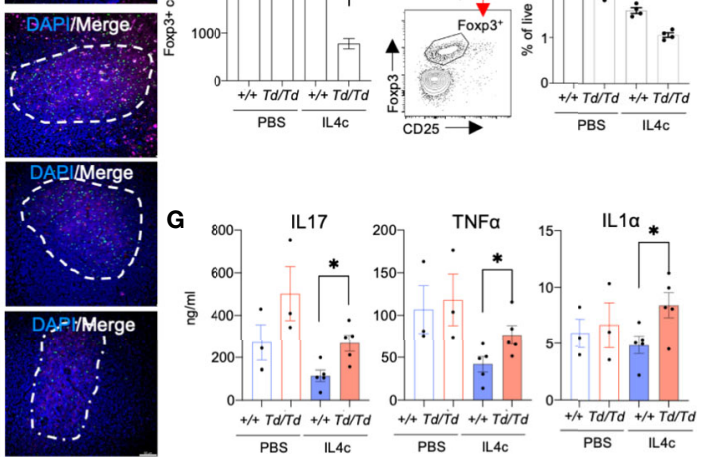

FIGURE 6 | Impaired splenic regulatory T cell responses in RELM $\alpha$-deficient mice are associated with increased inflammatory cytokines. Peritoneal cells and spleens from $\mathrm{R}^{+/+}$or $\mathrm{R} \alpha^{\mathrm{Td} / \mathrm{Td}}$ mice treated with PBS or IL-4c were recovered for evaluation of macrophage and T cell responses. (A) CD25 expression in SPM and LPM. (B) t-SNE -guided gating of peritoneal cavity LPM and SPM and analysis of CD25. (C, D) Immunofluorescent staining for CD3, Foxp3, RELM $\alpha$ and Td was performed on spleen sections and Foxp3+ cells were quantified. Bar: 50 $\mu \mathrm{m}$. (E) Gating strategy for effector and regulatory splenic T cells. (F) Frequency of Tregs in spleen evaluated ex vivo by intracellular staining for Foxp3. (G) Cytokine secretion was quantified from splenocytes stimulated with $\alpha$ CD3/ $\alpha$ CD28 for 72 hours. ${ }^{\star}, \mathrm{p} \leq 0.05 ;{ }^{* \star}, \mathrm{p} \leq 0.01 ;{ }^{\star \star *}, \mathrm{p} \leq 0.001 ;{ }^{\star \star \star \star}, \mathrm{p}<0.0001$.

of these cells in response to infection and inflammation $(55,57)$, but also reveal their role in immune homeostasis $(1,2,58,59)$. Peritoneal macrophages follow similar activation pathways to other macrophage lineages, where M1 macrophages activated by IFN $\gamma$ and TNF $\alpha$ have enhanced microbicidal or tumoricidal capacity and secrete high levels of pro-inflammatory cytokines and mediators (60), while IL-4 activated M2 macrophages reduce inflammation and contribute to tissue repair through secretion of IL-10 and TGF- $\beta(61,62)$. Although M2 macrophages have antiinflammatory roles, dysregulation of these signaling pathways also induce inflammation and immunopathology (38), which we investigated using the in vivo model of IL-4c induced peritonitis. RELM $\alpha$ is a signature marker of small peritoneal macrophages under homeostatic conditions and is highly expressed by small and large peritoneal macrophages in a type 2 cytokine environment. However, the potential contribution of RELM $\alpha$ to peritoneal macrophage activation, function, or effects on other immune or resident cells are unknown. We addressed this question by generating RELM $\alpha$ transgenic mice and found that RELM $\alpha$ expressed by peritoneal macrophages acts back to limit macrophage proliferation and activation. Macrophage-derived RELM $\alpha$ was also critical to support regulatory $\mathrm{T}$ cell proliferation and function.

Genetically deficient RELM $\alpha$ mice have been previously investigated $(28,29,31)$, and one study generated a RELM $\alpha$ cre recombinase mouse line that enabled fate mapping of RELM $\alpha$-expressing cells and diphtheria toxin-induced deletion of these cells (23). In the fate mapping RELM $\alpha$-cre mice, any cell in which the Retnla promoter has been active at any time, will have constitutive reporter protein expression throughout its lifespan, therefore potentially overrepresenting RELM $\alpha$ expression. In contrast, the reporter mouse model described here can reflect temporal changes in Retnla promoter activity. Here, we validate its utility as a faithful reporter by side-by-side analysis of TdTomato reporter and RELM $\alpha$ mRNA and protein expression. Compared to the RELM $\alpha$-cre mice, or other studies 
in helminth infection, we found that peritoneal macrophages were the dominant source of RELM $\alpha$, while eosinophils and B1 cells only expressed modest levels of RELM $\alpha$ in response to IL-4. Our data is consistent with RNA-seq and Immgen datasets that evaluate naïve immune cell subsets (13), where small peritoneal macrophages are the highest RELM $\alpha$ expressors. Compared to other mouse models, these mice offer the potential to specifically delete RELM $\alpha$ within individual cells. Furthermore, this alleviates the need for diphtheria toxin, that causes apoptosis and can have pathologic consequences independent of RELM $\alpha$ function. In this study, we validated our transgenic mice by crossing them to a universal cre-deleter mouse line, however, this transgenic mouse model provides the valuable opportunity in future studies to delete RELM $\alpha$ in specific cell-types.

Consistent with other studies demonstrating a protective and anti-inflammatory role for RELM $\alpha$, we show that RELM $\alpha$ is only expressed in naïve small peritoneal macrophage but is expressed by small and large peritoneal macrophages in IL-4-induced peritonitis. Within the peritoneal cavity, the main cell target of RELM $\alpha$ was the large peritoneal macrophage (LPM), where RELM $\alpha$ limited LPM proliferation and activation. This suggests that the same cell-type that produces RELM $\alpha$ is also its target, suggesting a macrophageintrinsic negative feedback loop. Since IL-4 drives significant expansion of peritoneal resident macrophages, it may be important for immune homeostasis and energy conservation to have internal feedback mechanisms, such as RELM $\alpha$, to keep this process in-check. For instance, sustained IL-4 exposure leads to immunopathology such as the macrophage activation syndrome, where splenomegaly is observed (38). The treatment regime in our studies involved only two IL-4c injections, however, $\mathrm{R} \alpha^{\mathrm{Td} / \mathrm{Td}}$ mice had already begun to exhibit immunopathologic features such as splenomegaly.

Gene expression analysis of the peritoneal macrophages from wild-type or RELM $\alpha$-deficient mice indicated dual effects for RELM $\alpha$ in limiting proliferation and promoting survival, while also regulating macrophage polarization. RELM $\alpha$-deficient macrophages had reduced expression of checkpoint inhibitors Dusp2, Batf $(43,63)$, but increased expression of anti-apoptotic signals such as Bcl2, Ctss and Pim2 (Figure S3B) $(64,65)$. RELM $\alpha$-deficient macrophages exhibited increased genes associated with functional myeloid pathways compared to wild-type macrophages, suggesting overall enhanced myeloid activation. These included increased expression of Cd74, Cd14, Mpeg1, Ccl6 and MHCII, increased complement factors associated with the coagulation cascade (C1qa, C1qb, C1qc), and higher expression of phagocytic and scavenger receptors (Mertk, Cd32, Cd16, Marco). Most of RELM $\alpha$-deficient macrophages upregulated genes associated M1 macrophage activation and antimicrobial function, including Cybb (66), Ifnar2 (67), Birc3 (68), Ccr5 (69) and Cd84 (70) (Figure S3B). In contrast, RELM $\alpha$ deficiency did not affect expression of other M2 macrophage signature genes such as Ym1 or Arginase, suggesting a regulatory effect of RELM $\alpha$ through inhibiting M1 activation, rather than promoting M2 activation.

Although gene expression analysis was performed on bulksorted peritoneal macrophages and did not distinguish monocyte- derived SPM from resident LPM, RELM $\alpha$ deficiency resulted in a heterogeneous macrophage phenotype with SPM and LPM markers. These included increased expression in RELM $\alpha$ deficient macrophages of LPM-specific genes such as Timd4 and Cxcl13, but also SPM-associated genes MHCII, CD62L (Sell), CD38 and CD74 (71, 72). IL-4c-induced peritonitis has been previously shown to be caused by resident LPM proliferation rather than the recruitment of blood monocytes $(17,73)$. In our studies both $\mathrm{R} \alpha^{\mathrm{Td} / \mathrm{Td}}$ SPM and LPM showed evidence of increased proliferative capacity with elevated Ki67 expression compared to $\mathrm{R}^{+/+}$macrophages, yet we did not observe significantly increased SPM numbers. It is possible that in the RELM $\alpha^{-/-}$environment, SPM were transitioning to LPM, as has been reported in inflammatory environments (71-73). Indeed, the absence of RELM $\alpha$ led to increased circulating inflammatory cytokines including TNF $\alpha$, IFN $\gamma$, IL- 6 and IL- $1 \alpha$, and exacerbated splenomegaly. Gene expression analysis revealed increased genes associated with growth factor signaling and angiogenesis (e.g. Pdgfb, Ncf2 and Fn1) in the RELM $\alpha$-deficient macrophages, which could have contributed to the splenomegaly.

The main regulatory effects of RELM $\alpha$ in limiting inflammation and immunopathology were observed following IL-4 treatment, however, MHCII genes (H2-Aa, H2-Ab1 and $\mathrm{H} 2-\mathrm{DMa})$ were consistently elevated in the RELM $\alpha$-deficient macrophages in both PBS and IL-4c treatment, suggesting a potential effect of RELM $\alpha$ on antigen presentation in a homeostatic or type 2 cytokine environment. To investigate the role of macrophageintrinsic RELM $\alpha$ in T cell responses, we performed splenocyte co-cultures with peritoneal macrophages from wild-type or RELM $\alpha$-deficient mice. RELM $\alpha$ deficiency had no significant effect on effector $\mathrm{T}$ cell responses, however, was unable to support optimal regulatory $\mathrm{T}$ cell proliferation. The direct mechanism underlying this defect is unclear, however, cytokine quantification revealed decreased Treg-associated cytokines GM-CSF (74) and IL10 , and conversely increased IL-6 in RELM $\alpha$-deficient macrophage co-cultures. These co-culture findings were supported by the in vivo studies, where there was reduced Treg frequency in the spleen, but enhanced Th17 cell responses. RELM $\alpha$-deficient macrophages had increased expression of the IL-2R (CD25), suggesting that they may limit IL-2 availability to the Tregs $(75,76)$, which was supported by our finding that IL-2 levels were significantly reduced in RELM $\alpha$ deficient macrophage co-cultures. However, further experiments are needed to functionally link CD25 expression with IL-2 consumption by RELM $\alpha$-deficient macrophages. Also, future investigation of the Tregs is warranted, such as their ability to suppress naïve T cells, and how their function is altered by RELM $\alpha$. Immunofluorescent staining validated Treg reduction in the spleen, which may have contributed to the splenomegaly by removal of this regulatory brake. Macrophages in the spleen express RELM $\alpha$, therefore splenic macrophage function may be similar to what was observed for the peritoneal cavity macrophages. An alternative possibility is that peritoneal macrophages migrate to the spleen, as prior studies observed peritoneal macrophage migration to other organs such as the liver in response to injury (2). Previous studies used bone marrow-derived macrophages or dendritic cells and in vivo helminth infection to address RELM $\alpha$ function in $\mathrm{T}$ cell 
polarization (28-30). Findings from these studies revealed many effects of RELM $\alpha$ on T cells, such as limiting Th2 cell polarization and promoting T cell-derived IL-10. Our studies support an immune regulatory role for RELM $\alpha$ on Tregs. However, we did not observe any differences in Th2 cell polarization, potentially because we interrogated the effect of RELM $\alpha$ on IL-4-induced responses, compared to the more complex outcomes and regulatory networks in helminth infection. Here, we further demonstrate the in vivo significance of resident peritoneal macrophages, which express significantly higher levels of RELM $\alpha$ than in vitro bone marrowderived cells. We also identify a targeted effect of RELM $\alpha$ on promoting Treg proliferation with functional consequences to limit spleen immunopathology. Overall, these studies identify dual effects of macrophage-intrinsic RELM $\alpha$ in limiting macrophage activation while supporting Treg responses with the overall effect of limiting type 2 cytokine-mediated immunopathology. Investigation of this macrophage-Treg axis, and how it is influenced by RELM $\alpha$, will be an important future direction to assess the biological significance of this interaction beyond IL-4c injection. Specifically, this immune regulatory role for RELM $\alpha$ in the peritoneal cavity may critically influence the outcome of type 2 cytokine-biased diseases such as helminth infection, injury and repair to visceral organs (77-80), but conversely may have impact in other settings where peritoneal macrophages and Tregs are detrimental such as in cancer metastases $(81,82)$.

\section{DATA AVAILABILITY STATEMENT}

The data has been uploaded to NCBI - accession number is GSE174606.

\section{REFERENCES}

1. Bain CC, Jenkins SJ. The Biology of Serous Cavity Macrophages. Cell Immunol (2018) 330:126-35. doi: 10.1016/j.cellimm.2018.01.003

2. Wang J, Kubes P. A Reservoir of Mature Cavity Macrophages That Can Rapidly Invade Visceral Organs to Affect Tissue Repair. Cell (2016) 165 (3):668-78. doi: 10.1016/j.cell.2016.03.009

3. Jackson-Jones LH, Bénézech C. Control of Innate-Like B Cell Location for Compartmentalised IgM Production. Curr Opin Immunol (2018) 50:9-13. doi: 10.1016/j.coi.2017.10.006

4. Wong K, Valdez PA, Tan C, Yeh S, Hongo JA, Ouyang W. Phosphatidylserine Receptor Tim-4 Is Essential for the Maintenance of the Homeostatic State of Resident Peritoneal Macrophages. Proc Natl Acad Sci USA (2010) 107 (19):8712-7. doi: 10.1073/pnas.0910929107

5. Rodriguez-Manzanet R, Sanjuan MA, Wu HY, Quintana FJ, Xiao S, Anderson AC, et al. T and B Cell Hyperactivity and Autoimmunity Associated With NicheSpecific Defects in Apoptotic Body Clearance in TIM-4-Deficient Mice. Proc Natl Acad Sci USA (2010) 107(19):8706-11. doi: 10.1073/pnas.0910359107

6. Newson J, Stables M, Karra E, Arce-Vargas F, Quezada S, Motwani M, et al. Resolution of Acute Inflammation Bridges the Gap Between Innate and Adaptive Immunity. Blood (2014) 124(11):1748-64. doi: 10.1182/blood-201403-562710

7. Huynh ML, Fadok VA, Henson PM. Phosphatidylserine-Dependent Ingestion of Apoptotic Cells Promotes TGF-Betal Secretion and the Resolution of Inflammation. J Clin Invest (2002) 109(1):41-50. doi: 10.1172/JCI11638

8. Butenko S, Satyanarayanan SK, Assi S, Schif-Zuck S, Sher N, Ariel A. Transcriptomic Analysis of Monocyte-Derived Non-Phagocytic Macrophages Favors a Role in Limiting Tissue Repair and Fibrosis. Front Immunol (2020) 11:405. doi: 10.3389/fimmu.2020.00405

\section{ETHICS STATEMENT}

The animal study was reviewed and approved by University of California Riverside Institutional Animal Care and Use Committee.

\section{AUTHOR CONTRIBUTIONS}

MN and JL conceptualized the study. JL and NL developed the methodology. JL, SK, and NL performed the investigation. MN and JL performed the formal analysis. MN and JL wrote the article. SK and DC edited the manuscript. MN and DC supervised the study. All authors contributed to the article and approved the submitted version.

\section{FUNDING}

This research was supported by the UCR School of Medicine (to $\mathrm{MN}$ ), and the National Institutes of Health (NIAID, R01AI153195 to MN). DC was supported in part by the National Institutes of Health (NICHD, R01HD091167).

\section{SUPPLEMENTARY MATERIAL}

The Supplementary Material for this article can be found online at: https://www.frontiersin.org/articles/10.3389/fimmu.2021. 710406/full\#supplementary-material

9. Jorch SK, Surewaard BG, Hossain M, Peiseler M, Deppermann C, Deng J, et al. Peritoneal GATA6+ Macrophages Function as a Portal for Staphylococcus Aureus Dissemination. J Clin Invest (2019) 129(11):464356. doi: $10.1172 / \mathrm{JCI} 127286$

10. Cailhier JF, Partolina M, Vuthoori S, Wu S, Ko K, Watson S, et al. Conditional Macrophage Ablation Demonstrates That Resident Macrophages Initiate Acute Peritoneal Inflammation. J Immunol (2005) 174(4):2336-42. doi: 10.4049/jimmunol.174.4.2336

11. Noy R, Pollard JW. Tumor-Associated Macrophages: From Mechanisms to Therapy. Immunity (2014) 41(1):49-61. doi: 10.1016/j.immuni. 2014.06.010

12. Jin Z, Zhu Z, Liu S, Hou Y, Tang M, Zhu P, et al. TRIM59 Protects Mice From Sepsis by Regulating Inflammation and Phagocytosis in Macrophages. Front Immunol (2020) 11:263. doi: 10.3389/fimmu.2020.00263

13. Kim KW, Williams JW, Wang YT, Ivanov S, Gilfillan S, Colonna M, et al. MHC II+ Resident Peritoneal and Pleural Macrophages Rely on IRF4 for Development From Circulating Monocytes. J Exp Med (2016) 213(10):19519. doi: 10.1084/jem.20160486

14. Jenkins SJ, Ruckerl D, Thomas GD, Hewitson JP, Duncan S, Brombacher F, et al. IL-4 Directly Signals Tissue-Resident Macrophages to Proliferate Beyond Homeostatic Levels Controlled by CSF-1. J Exp Med (2013) 210(11):2477-91. doi: 10.1084/jem.20121999

15. Holcomb IN, Kabakoff RC, Chan B, Baker TW, Gurney A, Henzel W, et al. FIZZ1, a Novel Cysteine-Rich Secreted Protein Associated With Pulmonary Inflammation, Defines a New Gene Family. EMBO J (2000) 19(15):4046-55. doi: 10.1093/emboj/19.15.4046

16. Pine GM, Batugedara HM, Nair MG. Here, There and Everywhere: ResistinLike Molecules in Infection, Inflammation, and Metabolic Disorders. Cytokine (2018) 110:442-51. doi: 10.1016/j.cyto.2018.05.014 
17. Jenkins SJ, Ruckerl D, Cook PC, Jones LH, Finkelman FD, van Rooijen N, et al. Local Macrophage Proliferation, Rather Than Recruitment From the Blood, is a Signature of TH2 Inflammation. Science (2011) 332(6035):1284-8. doi: 10.1126/science. 1204351

18. Bosurgi L, Cao YG, Cabeza-Cabrerizo M, Tucci A, Hughes LD, Kong Y, et al. Macrophage Function in Tissue Repair and Remodeling Requires IL-4 or IL13 With Apoptotic Cells. Science (2017) 356(6342):1072-6. doi: 10.1126/ science.aai8132

19. Torres-Capelli M, Marsboom G, Li QO, Tello D, Rodriguez FM, Alonso T, et al. Role of Hif $2 \alpha$ Oxygen Sensing Pathway in Bronchial Epithelial Club Cell Proliferation. Sci Rep (2016) 6. doi: 10.1038/srep25357

20. Liu $\mathrm{T}, \mathrm{Yu} \mathrm{H}$, Ullenbruch $\mathrm{M}$, Jin $\mathrm{H}$, Ito $\mathrm{T}, \mathrm{Wu} \mathrm{Z}$, et al. The In Vivo Fibrotic Role of FIZZ1 in Pulmonary Fibrosis. PloS One (2014) 9(2):e88362. doi: 10.1371/ journal.pone.0088362

21. Lin Q, Fan C, Skinner JT, Hunter EN, Macdonald AA, Illei PB, et al. Relm $\alpha$ Licenses Macrophages for Damage-Associated Molecular Pattern Activation to Instigate Pulmonary Vascular Remodeling. J Immunol (2019) 203 (11):2862-71. doi: 10.4049/jimmunol.1900535

22. Batugedara HM, Li J, Chen G, Lu D, Patel JJ, Jang JC, et al. Hematopoietic CellDerived Relm $\alpha$ Regulates Hookworm Immunity Through Effects on Macrophages. J Leukoc Biol (2018) 104(4):855-69. doi: 10.1002/JLB.4A0917-369RR

23. Krljanac B, Schubart C, Naumann R, Wirtz S, Culemann S, Krönke G, et al. Relm $\alpha$-Expressing Macrophages Protect Against Fatal Lung Damage and Reduce Parasite Burden During Helminth Infection. Sci Immunol (2019) 4 (35). doi: 10.1126/sciimmunol.aau3814

24. Sutherland TE, Rückerl D, Logan N, Duncan S, Wynn TA, Allen JE. Ym1 Induces Relm $\alpha$ and Rescues IL-4ro Deficiency in Lung Repair During Nematode Infection. PloS Pathog (2018) 14(11):e1007423. doi: 10.1371/ journal.ppat.1007423

25. Chen G, Wang SH, Jang JC, Odegaard JI, Nair MG. Comparison of Relm $\alpha$ and Relm $\beta$ Single- and Double-Gene-Deficient Mice Reveals That Relm $\alpha$ Expression Dictates Inflammation and Worm Expulsion in Hookworm Infection. Infect Immun (2016) 84(4):1100-11. doi: 10.1128/IAI.01479-15

26. Knipper JA, Willenborg S, Brinckmann J, Bloch W, Maaß T, Wagener R, et al. Interleukin-4 Receptor $\alpha$ Signaling in Myeloid Cells Controls Collagen Fibril Assembly in Skin Repair. Immunity (2015) 43(4):803-16. doi: 10.1016/ j.immuni.2015.09.005

27. Kim SY, Nair MG. Macrophages in Wound Healing: Activation and Plasticity. Immunol Cell Biol (2019) 97(3):258-67. doi: 10.1111/imcb.12236

28. Pesce JT, Ramalingam TR, Wilson MS, Mentink-Kane MM, Thompson RW, Cheever AW, et al. Retnla (Relmalpha/Fizz1) Suppresses Helminth-Induced Th2-Type Immunity. PloS Pathog (2009) 5(4):e1000393. doi: 10.1371/ journal.ppat.1000393

29. Nair MG, Du Y, Perrigoue JG, Zaph C, Taylor JJ, Goldschmidt M, et al. Alternatively Activated Macrophage-Derived RELM-\{Alpha\} Is a Negative Regulator of Type 2 Inflammation in the Lung. J Exp Med (2009) 206(4):93752. doi: $10.1084 /$ jem. 20082048

30. Cook PC, Jones LH, Jenkins SJ, Wynn TA, Allen JE, MacDonald AS. Alternatively Activated Dendritic Cells Regulate CD4+ T-Cell Polarization In Vitro and In Vivo. Proc Natl Acad Sci USA (2012) 109(25):9977-82. doi: 10.1073/pnas.1121231109

31. Harris TA, Gattu S, Propheter DC, Kuang Z, Bel S, Ruhn KA, et al. Resistin-Like Molecule $\alpha$ Provides Vitamin-A-Dependent Antimicrobial Protection in the Skin. Cell Host Microbe (2019) 25(6):777-88.e8. doi: 10.1016/j.chom.2019.04.004

32. Xu ZL, Mizuguchi H, Mayumi T, Hayakawa T. Woodchuck Hepatitis Virus Post-Transcriptional Regulation Element Enhances Transgene Expression From Adenovirus Vectors. Biochim Biophys Acta (2003) 1621(3):266-71. doi: 10.1016/s0304-4165(03)00078-3

33. Fujiyama S, Nakahashi-Oda C, Abe F, Wang Y, Sato K, Shibuya A. Identification and Isolation of Splenic Tissue-Resident Macrophage SubPopulations by Flow Cytometry. Int Immunol (2019) 31(1):51-6. doi: 10.1093/intimm/dxy064

34. Chen KE, Lainez NM, Nair MG, Coss D. Visceral Adipose Tissue Imparts Peripheral Macrophage Influx Into the Hypothalamus. J Neuroinflamm (2021) 18(1):140. doi: 10.1186/s12974-021-02183-2

35. Tomfohr J, Lu J, Kepler TB. Pathway Level Analysis of Gene Expression Using Singular Value Decomposition. BMC Bioinf (2005) 6:225. doi: 10.1186/14712105-6-225
36. Babicki S, Arndt D, Marcu A, Liang Y, Grant JR, Maciejewski A, et al. Heatmapper: Web-Enabled Heat Mapping for All. Nucleic Acids Res (2016) 44 (W1):W147-53. doi: 10.1093/nar/gkw419

37. Liu M, Silva-Sanchez A, Randall TD, Meza-Perez S. Specialized Immune Responses in the Peritoneal Cavity and Omentum. J Leukoc Biol (2021) 109 (4):717-29. doi: 10.1002/JLB.5MIR0720-271RR

38. Milner JD, Orekov T, Ward JM, Cheng L, Torres-Velez F, Junttila I, et al. Sustained IL-4 Exposure Leads to a Novel Pathway for Hemophagocytosis, Inflammation, and Tissue Macrophage Accumulation. Blood (2010) 116 (14):2476-83. doi: 10.1182/blood-2009-11-255174

39. Panova V, Gogoi M, Rodriguez-Rodriguez N, Sivasubramaniam M, Jolin HE, Heycock MWD, et al. Group-2 Innate Lymphoid Cell-Dependent Regulation of Tissue Neutrophil Migration by Alternatively Activated Macrophage-Secreted Ear11. Mucosal Immunol (2021) 14(1):26-37. doi: 10.1038/s41385-020-0298-2

40. Dickinson RJ, Keyse SM. Diverse Physiological Functions for Dual-Specificity MAP Kinase Phosphatases. J Cell Sci (2006) 119(22):4607-15. doi: 10.1242/jcs.03266

41. Ansel KM, Harris RB, Cyster JG. CXCL13 is Required for B1 Cell Homing, Natural Antibody Production, and Body Cavity Immunity. Immunity (2002) 16(1):67-76. doi: 10.1016/s1074-7613(01)00257-6

42. Wei W, Jiao Y, Postlethwaite A, Stuart JM, Wang Y, Sun D, et al. DualSpecificity Phosphatases 2: Surprising Positive Effect at the Molecular Level and a Potential Biomarker of Diseases. Genes Immun (2013) 14(1):1-6. doi: 10.1038/gene.2012.54

43. Lin SC, Chien CW, Lee JC, Yeh YC, Hsu KF, Lai YY, et al. Suppression of Dual-Specificity Phosphatase-2 by Hypoxia Increases Chemoresistance and Malignancy in Human Cancer Cells. J Clin Invest (2011) 121(5):1905-16. doi: 10.1172/JCI44362

44. Zhang J, Lo C. Regulation of Fibronectin Expression by PDGF-BB and IGF-I in Cultured Rat Thoracic Aortic Adventitial Fibroblasts. Cell Biol Int (1995) 19 (6):517-25. doi: 10.1006/cbir.1995.1096

45. A-Gonzalez N, Quintana JA, García-Silva S, Mazariegos M, González de la Aleja A, Nicolás-Ávila JA, et al. Phagocytosis Imprints Heterogeneity in Tissue-Resident Macrophages. J Exp Med (2017) 214(5):1281-96. doi: $10.1084 /$ jem. 20161375

46. Egami Y. Molecular Imaging Analysis of Rab GTPases in the Regulation of Phagocytosis and Macropinocytosis. Anat Sci Int (2016) 91(1):35-42. doi: 10.1007/s12565-015-0313-y

47. Mantegazza AR, Magalhaes JG, Amigorena S, Marks MS. Presentation of Phagocytosed Antigens by MHC Class I and II. Traffic (2013) 14(2):135-52. doi: $10.1111 /$ tra.12026

48. Schaer DJ, Schleiffenbaum B, Kurrer M, Imhof A, Bächli E, Fehr J, et al. Soluble Hemoglobin-Haptoglobin Scavenger Receptor CD163 as a LineageSpecific Marker in the Reactive Hemophagocytic Syndrome. Eur J Haematol (2005) 74(1):6-10. doi: 10.1111/j.1600-0609.2004.00318.x

49. Fuentes-Duculan J, Suárez-Fariñas M, Zaba LC, Nograles KE, Pierson KC, Mitsui H, et al. A Subpopulation of CD163-Positive Macrophages is Classically Activated in Psoriasis. J Invest Dermatol (2010) 130(10):2412-22. doi: 10.1038/jid.2010.165

50. Culemann S, Grüneboom A, Nicolás-Ávila J, Weidner D, Lämmle KF, Rothe $\mathrm{T}$, et al. Locally Renewing Resident Synovial Macrophages Provide a Protective Barrier for the Joint. Nature (2019) 572(7771):670-5. doi: 10.1038/s41586-019-1471-1

51. Skytthe MK, Graversen JH, Moestrup SK. Targeting of CD163. Int J Mol Sci (2020) 21(15):1-32. doi: 10.3390/ijms21155497

52. Li J, Lu E, Yi T, Cyster JG. EBI2 Augments Tfh Cell Fate by Promoting Interaction With IL-2-Quenching Dendritic Cells. Nature (2016) 533 (7601):110-4. doi: 10.1038/nature17947

53. Ghosn EE, Cassado AA, Govoni GR, Fukuhara T, Yang Y, Monack DM, et al. Two Physically, Functionally, and Developmentally Distinct Peritoneal Macrophage Subsets. Proc Natl Acad Sci USA (2010) 107(6):2568-73. doi: 10.1073/pnas.0915000107

54. Cassado A, D’Império Lima MR, Bortoluci KR. Revisiting Mouse Peritoneal Macrophages: Heterogeneity, Development, and Function. Front Immunol (2015) 6:225. doi: 10.3389/fimmu.2015.00225

55. Zhang N, Czepielewski RS, Jarjour NN, Erlich EC, Esaulova E, Saunders BT, et al. Expression of Factor V by Resident Macrophages Boosts Host Defense in the Peritoneal Cavity. J Exp Med (2019) 216(6):1291-300. doi: 10.1084/ jem.20182024 
56. Zindel J, Peiseler M, Hossain M, Deppermann C, Lee WY, Haenni B, et al. Primordial GATA6 Macrophages Function as Extravascular Platelets in Sterile Injury. Science (2021) 371(6533):1-12. doi: 10.1126/science.abe0595

57. Dahdah A, Gautier G, Attout T, Fiore F, Lebourdais E, Msallam R, et al. Mast Cells Aggravate Sepsis by Inhibiting Peritoneal Macrophage Phagocytosis. J Clin Invest (2014) 124(10):4577-89. doi: 10.1172/JCI75212

58. Roberts AW, Lee BL, Deguine J, John S, Shlomchik MJ, Barton GM. TissueResident Macrophages Are Locally Programmed for Silent Clearance of Apoptotic Cells. Immunity (2017) 47(5):913-27.e6. doi: 10.1016/j.immuni. 2017.10.006

59. Okabe Y, Medzhitov R. Tissue-Specific Signals Control Reversible Program of Localization and Functional Polarization of Macrophages. Cell (2014) 157 (4):832-44. doi: 10.1016/j.cell.2014.04.016

60. Mosser DM, Edwards JP. Exploring the Full Spectrum of Macrophage Activation. Nat Rev Immunol (2008) 8(12):958-69. doi: 10.1038/nri2448

61. Liu Q, Tian Y, Zhao X, Jing H, Xie Q, Li P, et al. NMAAP1 Expressed in BCGActivated Macrophage Promotes M1 Macrophage Polarization. Mol Cells (2015) 38(10):886-94. doi: 10.14348/molcells.2015.0125

62. Mao R, Wang C, Zhang F, Zhao M, Liu S, Liao G, et al. Peritoneal M2 Macrophage Transplantation as a Potential Cell Therapy for Enhancing Renal Repair in Acute Kidney Injury. J Cell Mol Med (2020) 24(6):3314-27. doi: $10.1111 / \mathrm{jcmm} .15005$

63. Quigley M, Pereyra F, Nilsson B, Porichis F, Fonseca C, Eichbaum Q, et al. Transcriptional Analysis of HIV-Specific CD8+ T Cells Shows That PD-1 Inhibits T Cell Function by Upregulating BATF. Nat Med (2010) 16 (10):1147-51. doi: 10.1038/nm.2232

64. Salpeter SJ, Pozniak Y, Merquiol E, Ben-Nun Y, Geiger T, Blum G. A Novel Cysteine Cathepsin Inhibitor Yields Macrophage Cell Death and Mammary Tumor Regression. Oncogene (2015) 34(50):6066-78. doi: 10.1038/ onc. 2015.51

65. Asano J, Nakano A, Oda A, Amou H, Hiasa M, Takeuchi K, et al. The Serine/ Threonine Kinase Pim-2 Is a Novel Anti-Apoptotic Mediator in Myeloma Cells. Leukemia (2011) 25(7):1182-8. doi: 10.1038/leu.2011.60

66. Gerrick KY, Gerrick ER, Gupta A, Wheelan SJ, Yegnasubramanian S, Jaffee EM. Transcriptional Profiling Identifies Novel Regulators of Macrophage Polarization. PloS One (2018) 13(12):e0208602. doi: 10.1371/journal. pone.0208602

67. Orecchioni M, Ghosheh Y, Pramod AB, Ley K. Macrophage Polarization: Different Gene Signatures in M1(LPS+) vs. Classically M2(LPS-) Vs Alternatively Activated Macrophages Front Immunol (2019) 10:1084. doi: 10.3389/fimmu.2019.01084

68. Conte D, Holcik M, Lefebvre CA, Lacasse E, Picketts DJ, Wright KE, et al. Inhibitor of Apoptosis Protein Ciap2 is Essential for LipopolysaccharideInduced Macrophage Survival. Mol Cell Biol (2006) 26(2):699-708. doi: 10.1128/MCB.26.2.699-708.2006

69. Shaheen ZR, Christmann BS, Stafford JD, Moran JM, Buller RML, Corbett JA. CCR5 is a Required Signaling Receptor for Macrophage Expression of Inflammatory Genes in Response to Viral Double-Stranded RNA. Am J Physiol Regul Integr Comp Physiol (2019) 316(5):R525-34. doi: 10.1152/ ajpregu.00019.2019

70. Sintes J, Romero X, de Salort J, Terhorst C, Engel P. Mouse CD84 is a PanLeukocyte Cell-Surface Molecule That Modulates LPS-Induced Cytokine Secretion by Macrophages. J Leukoc Biol (2010) 88(4):687-97. doi: 10.1189/ jlb.1109756
71. Louwe PA, Badiola Gomez L, Webster H, Perona-Wright G, Bain CC, Forbes SJ, et al. Recruited Macrophages That Colonize the Post-Inflammatory Peritoneal Niche Convert Into Functionally Divergent Resident Cells. Nat Commun (2021) 12(1):1770. doi: 10.1038/s41467-021-21778-0

72. Bain CC, Gibson DA, Steers NJ, Boufea K, Louwe PA, Doherty C, et al. Rate of Replenishment and Microenvironment Contribute to the Sexually Dimorphic Phenotype and Function of Peritoneal Macrophages. Sci Immunol (2020) 5 (48). doi: 10.1126/sciimmunol.abc4466

73. Liu Z, Gu Y, Chakarov S, Bleriot C, Kwok I, Chen X, et al. Fate Mapping via Ms4a3-Expression History Traces Monocyte-Derived Cells. Cell (2019) 178 (6):1509-1525.e19. doi: 10.1016/j.cell.2019.08.009

74. Kared H, Leforban B, Montandon R, Renand A, Layseca Espinosa E, Chatenoud L, et al. Role of GM-CSF in Tolerance Induction by Mobilized Hematopoietic Progenitors. Blood (2008) 112(6):2575-8. doi: 10.1182/blood2008-02-140681

75. Kryczek I, Wei S, Zou L, Altuwaijri S, Szeliga W, Kolls J, et al. Cutting Edge: Th17 and Regulatory T Cell Dynamics and the Regulation by IL-2 in the Tumor Microenvironment. J Immunol (2007) 178(11):6730-3. doi: 10.4049/ jimmunol.178.11.6730

76. Driesen J, Popov A, Schultze JL. CD25 as an Immune Regulatory Molecule Expressed on Myeloid Dendritic Cells. Immunobiology (2008) 213(9-10). doi: 10.1016/j.imbio.2008.07.026

77. Spellberg B, Edwards JE. Type 1/Type 2 Immunity in Infectious Diseases. Clin Infect Dis (2001) 32(1):76-102. doi: 10.1086/317537

78. Boothby IC, Cohen JN, Rosenblum MD. Regulatory T Cells in Skin Injury: At the Crossroads of Tolerance and Tissue Repair. Sci Immunol (2020) 5(47). doi: 10.1126/sciimmunol.aaz9631

79. Xiao F, Liu X, Guo SW. Platelets and Regulatory T Cells May Induce a Type 2 Immunity That Is Conducive to the Progression and Fibrogenesis of Endometriosis. Front Immunol (2020) 11:610963. doi: 10.3389/ fimmu.2020.610963

80. Wang Z, Hao C, Zhuang Q, Zhan B, Sun X, Huang J, et al. Excretory/Secretory Products From Trichinella Spiralis Adult Worms Attenuated DSS-Induced Colitis in Mice by Driving PD-1-Mediated M2 Macrophage. Front Immunol (2020) 11:563784. doi: 10.3389/fimmu.2020.563784

81. Mikuła-Pietrasik J, Uruski P, Tykarski A, Ksiązek K. The Peritoneal "Soil” for a Cancerous "Seed": A Comprehensive Review of the Pathogenesis of Intraperitoneal Cancer Metastases. Cell Mol Life Sci (2018) 75(3):509-25. doi: 10.1007/s00018-017-2663-1

82. Movahedi K, Laoui D, Gysemans C, Baeten M, Stangé G, Van den Bossche J, et al. Different Tumor Microenvironments Contain Functionally Distinct Subsets of Macrophages Derived From Ly6C(high) Monocytes. Cancer Res (2010) 70(14):5728-39. doi: 10.1158/0008-5472.CAN-09-4672

Conflict of Interest: The authors declare that the research was conducted in the absence of any commercial or financial relationships that could be construed as a potential conflict of interest.

Copyright (c) $2021 \mathrm{Li}$, Kim, Lainez, Coss and Nair. This is an open-access article distributed under the terms of the Creative Commons Attribution License (CC BY). The use, distribution or reproduction in other forums is permitted, provided the original author(s) and the copyright owner(s) are credited and that the original publication in this journal is cited, in accordance with accepted academic practice. No use, distribution or reproduction is permitted which does not comply with these terms. 